\title{
Regulated Vesicular Trafficking of Specific PCDH15 and VLGR1 Variants in Auditory Hair Cells
}

\author{
Marisa Zallocchi, ${ }^{1}$ Duane Delimont, ${ }^{1}$ Daniel T. Meehan, ${ }^{1}$ and Dominic Cosgrove ${ }^{1,2}$ \\ ${ }^{1}$ Boys Town National Research Hospital, Omaha, Nebraska 68131, and ${ }^{2}$ University of Nebraska Medical Center, Omaha, Nebraska 68198
}

Usher syndrome is a genetically heterogeneous disorder characterized by hearing and balance dysfunction and progressive retinitis pigmentosa. Mouse models carrying mutations for the nine Usher-associated genes have splayed stereocilia, and some show delayed maturation of ribbon synapses suggesting these proteins may play different roles in terminal differentiation of auditory hair cells. The presence of the Usher proteins at the basal and apical aspects of the neurosensory epithelia suggests the existence of regulated trafficking through specific transport proteins and routes. Immature mouse cochleae and UB/OC-1 cells were used in this work to address whether specific variants of PCDH15 and VLGR1 are being selectively transported to opposite poles of the hair cells. Confocal colocalization studies between apical and basal vesicular markers and the different PCDH15 and VLGR1 variants along with sucrose density gradients and the use of vesicle trafficking inhibitors show the existence of Usher protein complexes in at least two vesicular subpools. The apically trafficked pool colocalized with the early endosomal vesicle marker, rab5, while the basally trafficked pool associated with membrane microdomains and SNAP25. Moreover, coimmunoprecipitation experiments between SNAP25 and VLGR1 show a physical interaction of these two proteins in organ of Corti and brain. Collectively, these findings establish the existence of a differential vesicular trafficking mechanism for specific Usher protein variants in mouse cochlear hair cells, with the apical variants playing a potential role in endosomal recycling and stereocilia development/maintenance, and the basolateral variants involved in vesicle docking and/or fusion through SNAP25-mediated interactions.

\section{Introduction}

Mutations within the Usher genes cause an autosomal recessive disorder called Usher syndrome (USH) characterized by congenital deafness and progressive retinitis pigmentosa (Hallgren, 1959; Boughman et al., 1983). Of the 11 loci associated with this disease, nine genes have been identified and the subcellular distribution of the encoded proteins partially characterized in both types of neurosensory cells, hair cells and photoreceptors (Petit, 2001; Reiners et al., 2006). In vitro and in vivo analysis of the Usher protein interactions along with immunolocalization studies suggest the existence of protein complexes comprised of specific Usher isoforms. The splayed stereocilia phenotype and the abnormalities observed in zebrafish and Usher mouse models strongly point to a role in hair bundle morphogenesis and synaptic maturation for the Usher complexes (Seiler and Nicolson,

\footnotetext{
Received March 13, 2012; revised July 20, 2012; accepted Aug. 3, 2012.

Author contributions: M.Z. and D.C. designed research; M.Z., D.D., and D.T.M. performed research; M.Z., D.D., D.T.M., and D.C. analyzed data; M.Z. and D.C. wrote the paper.

This work was supported by NIH Grants R01 DC004844 to D.C. and 5 P20 RR018788-08. Confocal microscopy was conducted at the Integrative Biological Imaging Facility, Creighton University, Omaha, NE (5P20RR016469, NCRR, NIH and 8P20GM103427, NIGMS, NIH. This investigation is solely the responsibility of the authors and does not necessarily represent the official views of NIGMS or NIH). We gratefully acknowledge Dr. M. Holley for the UB/OC-1 cells, Dr. U. Muller for the PCDH15(M) antibody, and Dr. J. Lippincott-Schwartz for the Rab5079L construct, Skip Kennedy for figure preparation, and Linda Cheung and Brianna Johnson for technical assistance.

The authors declare no competing financial interests.

Correspondence should be addressed to Dominic Cosgrove, National Usher Syndrome Center, Boys Town National Research Hospital, 555 N 30th Street, Omaha, NE 68131. E-mail: dominic.cosgrove@boystown.org.

DOI:10.1523/JNEUROSCI.1242-12.2012

Copyright $\odot 2012$ the authors $\quad 0270-6474 / 12 / 3213841-19 \$ 15.00 / 0$
}

1999; Seiler et al., 2005; Zallocchi et al., 2009, 2012; Gregory et al., 2011; Phillips et al., 2011).

Defects in the $\mathrm{Ca}^{2+}$-dependent cell adhesion molecule protocadherin-15 (PCDH15) cause USH1F and nonsyndromic deafness DFNB23 (Ahmed et al., 2003, 2008). PCDH15 in coordination with cadherin-23 (CDH23, USH1D) form the transient kinociliary links and the tip links that gate the mechanotransduction channels in auditory hair cells (Kazmierczak et al., 2007). The very large G-protein-coupled receptor-1 (VLGR1) is a component of the ankle links present during stereocilia development, and mutations within its gene cause USH2C and audiogenic epilepsy (Skradski et al., 2001; Staub et al., 2002; McGee et al., 2006; Michalski et al., 2007). Multiple isoforms for all three Usher proteins have been described, with some of them also playing a role in hair cell synaptic maturation and function (Petit, 2001; Lagziel et al., 2009; Reiners et al., 2006; Phillips et al., 2011; Gregory et al., 2011; Zallocchi et al., 2009, 2012).

The presence of the Usher proteins in both the basal and apical poles of the hair cells (and photoreceptors) suggests a regulated trafficking inferring a specific recognition/association pathway for distinct vesicular subpools. Using antibody preparations to PCDH15 and VLGR1 against distinct regions of the two proteins, we examined the distribution of specific Usher variants at the apical and basal aspects of cochlear hair cells. We were able to identify distinct vesicle pools that are being trafficked to either the basal or apical aspects of immature cochlear hair cells. Each pool contains specific variants of VLGR1 and PCDH15. One vesicle pool associates with ADP-ribosylation factor 1 (Arf1)-positive vesicles, colocalizes with the endosomal GTPase, rab5, and is 
A

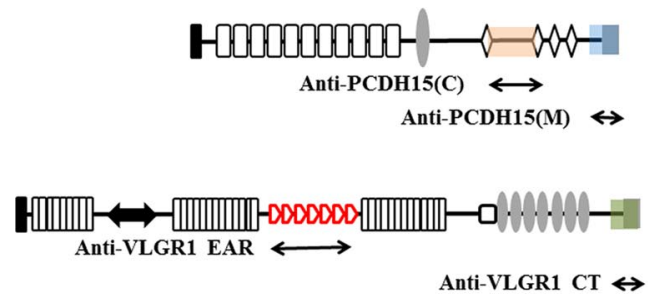

B IB PCDH15 (M)

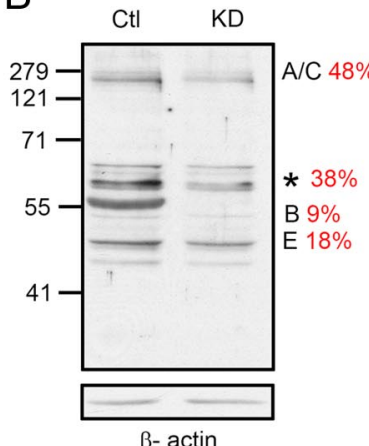

IB VLGR1 CT

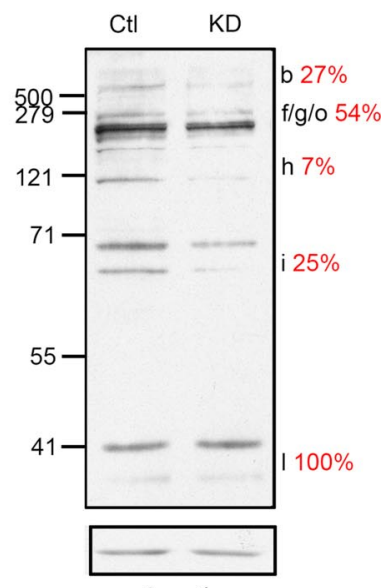

C
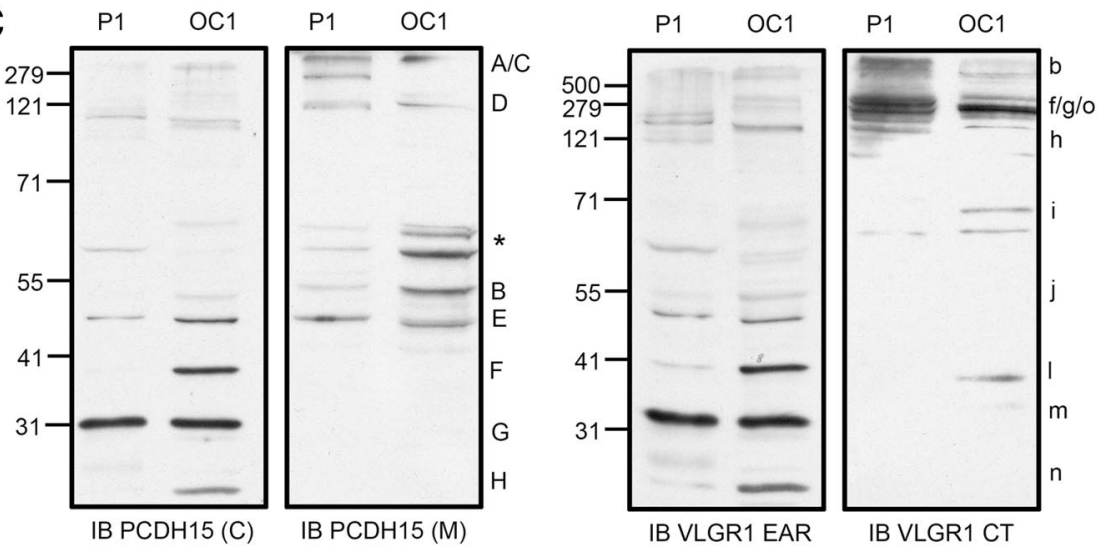

D

\begin{tabular}{c|cc} 
PCDH15 & $\begin{array}{c}\text { C-terminal region } \\
\text { (aa 1490-1709) }\end{array}$ & $\begin{array}{c}\text { C-terminal region } \\
\text { (aa 1823-1943) }\end{array}$ \\
\hline A & + & + \\
C & + & + \\
D & + & + \\
B & + & + \\
E & + & + \\
F & + & - \\
G & + & - \\
H & + & - \\
$*$ & +- & +
\end{tabular}

\begin{tabular}{c|cc} 
VLGR1 & EAR domain & C-terminal region \\
\hline $\boldsymbol{b}$ & + & + \\
$f / g / \boldsymbol{o}$ & + & + \\
$\boldsymbol{h}$ & + & + \\
$\boldsymbol{i}$ & + & + \\
$j$ & + & - \\
$\boldsymbol{l}$ & + & + \\
$\boldsymbol{m}$ & + & - \\
$\boldsymbol{n}$ & + & -
\end{tabular}

Figure 1. Comparative analyses of PCDH15 and VLGR1 variants in cochlea and UB/OC-1 cells. $A$, Structure and domains (not to scale) of full-length PCDH15 and VLGR1. Regions comprising the peptide immunogens are indicated with double-headed arrows and by colored shadows. SS, Signal sequence; EC, extracellular cadherin repeats; TM, transmembrane domain; PRM, proline-rich motif; PBM, PDZ-binding motif; GPS, G-protein-coupled receptor proteolytic site; CalX-b, $\mathrm{Ca}^{2+}$-binding domain of the $\mathrm{Na}^{+} / \mathrm{Ca}^{2+}$ exchanger molecule; LamG/TspN/PTX, laminin-G/thrombospondin-N/pentraxin homology domains; EAR/EPTP, epilepsy-associated repeat/epitempin repeat. $\boldsymbol{B}$, Western blot analysis of scrambled (Ctl) and Usher specific knock-down (KD) cells immunoblotted for anti-PCDH15(M) [IB PCDH15(M)] or anti-VLGR1 CT (IB VLGR1 CT). Immunoblots were stripped and reprobed for $\beta$-actin as a loading control. Red numbers represent the percentage of expression relative to the scrambled and after normalization with $\beta$-actin. C, Protein lysates from P1 cochleae (P1) or UB/OC-1 cells (OC1) were immunoblotted for anti-PCDH15(C) and anti-PCDH15(M) (left panels) or VLGR1 EAR and anti-VLGR1 CT (right panels). D, Summary table of the different Usher variants with the corresponding putative protein region. " + " denotes presence of that particular domain. " - " denotes absence of that particular domain." $+1-$ " denotes presence of that particular domain in at least one of the variants. Molecular weight markers (kDa) are indicated to the left and name of the variant to the right. Variants were named according to previously establish nomenclature systems (Ahmed et al., 2003, 2006; McMillan and White, 2004; Reiners et al., 2005; Kazmierczak et al., 2007; Zallocchi et al., 2012). Asterisks denote novel specific PCDH15 variants.

trafficked to the apical aspect of cochlear hair cells. The second pool is defined by its partial association with membrane microdomains and adaptin-1 (AP-1)-positive post-trans-Golgi vesicles and by its interaction with SNAP25 (synaptosomalassociated protein of $25 \mathrm{kDa}$ ). This pool is trafficked to the basal aspect of the hair cells.

These newly found associations with distinct vesicle/membrane markers link for the first time a differential trafficking mechanism for the Usher proteins, in which the basolaterally trafficked variants may be involved in docking/fusion functions while the apically trafficked variants may play a role in the endosomal recycling and stereocilia maintenance pathways.

\section{Materials and Methods}

Animals

Postnatal day 1 (P1) and P3 wild-type mice of either sex were in the 129Sv/J strain, obtained from Jackson Laboratories, and bred in-house. Experiments using mice were performed under an approved Institutional Animal Care and Use Committee protocol, and every effort was made to minimize pain and discomfort.

\section{Antibodies}

The rabbit polyclonal PCDH15(C), VLGR1 EAR, and VLGR1 CT antibodies were developed in our laboratory, described, and characterized previously (McGee et al., 2006; Maerker et al., 2008; Zallocchi et al., 2010, 2012). Anti-PCDH15(C) recognizes an immunogen region within the 


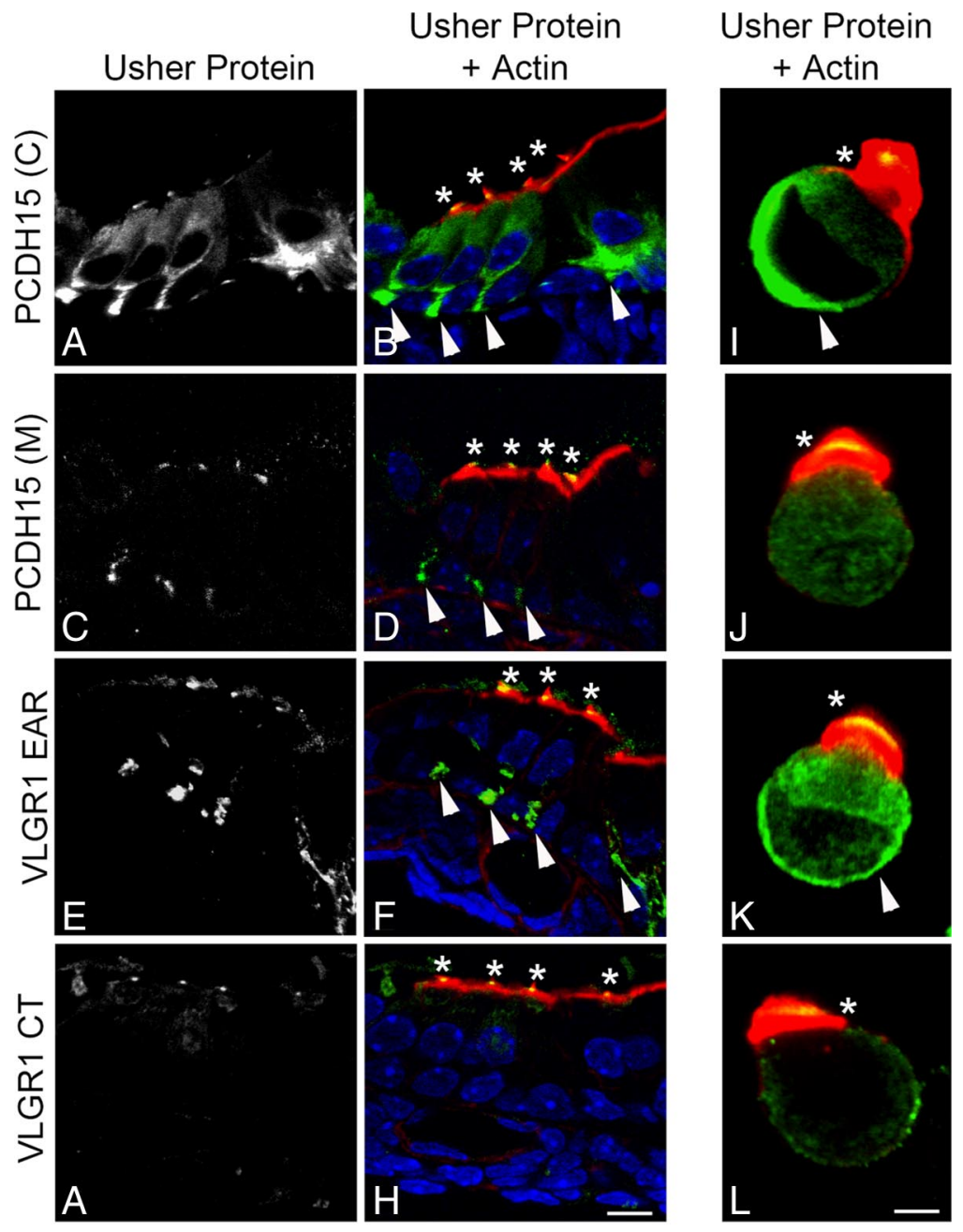

\begin{tabular}{c|ccc} 
& ST & BM & NT \\
\hline PCDH15(C) & + & + & + \\
PCDH15(M) & + & - & + \\
VLGR1 EAR & + & + & + \\
VLGR1 CT & + & - & -
\end{tabular}

Figure 2. Immunolocalization analysis of the Usher protein variants in mouse cochlea. P1 cochlea cross-sections and isolated hair cells immunostained with the different Usher protein antibodies (green) and counterstained with phalloidin for $F$-actin (red).

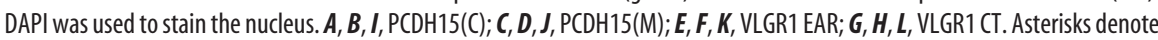
Usher protein immunostaining in stereocilia. Arrowheads denote basal expression of the Usher proteins. Scale bars: $\boldsymbol{A}-\boldsymbol{H}, 10 \mu \mathrm{m}$ $I-L, 2 \mu \mathrm{m}$. Table summarizes the immunofluorescence results where " + " denotes expression and " - " denotes lack of expression. ST, Stereocilia; BM, basolateral membrane; NT, neuronal terminal.

cytoplasmic domain between amino acids 1490-1709 of PCDH15 CD1 isoform (Ahmed et al., 2003, 2006). The immunogen regions for the VLGR1 antibodies include amino acids 3245-3421 comprising the EAR/ EPTP domain, for anti-VLGR1 EAR, and amino acids 6153-6298 in the C-terminal region for anti-VLGR1 CT. The rabbit polyclonal anti-
PCDH15(M) that recognizes the cytoplasmic domain region between amino acids 1823-1943 of PCDH15 isoform CD1 was kindly provided by Dr. U. Muller (Scripps Research Institute) (Senften et al., 2006).

Other antibodies used in this work were mouse anti-SNAP25 (Abcam), goat anti-rab5A (Santa Cruz Biotechnology), mouse anti-ribeye (BD Biosciences), chicken anti-GFP (Novus Biologicals), mouse IgM anti- $\beta$-tubulin (BD Biosciences), and mouse anti-rab5 and mouse anti- $\beta$-actin (Sigma).

Antibody qualification for the specific variants detected by PCDH15(M) and VLGR1 CT antibody preparations Differentiated UB/OC-1 (University of Bristol/ Organ of Corti- 1$)$ cells $\left(\sim 1 \times 10^{6}\right)$ were electroporated with $1 \mu \mathrm{g}$ of the scrambled siRNA or siRNAs specific for PCDH15 or VLGR1. The specific siRNAs were directed to the sequences used to derive the peptide immunogens for each Usher transcript and were designed by Applied Biosystems. Sense and antisense sequences of the corresponding siRNAs are as follows: PCDH15(M): 5'-CGUUUGAUGGCGUGCAAGAtt-3'/5'-UC UUGCACGCCAUCAAACGct-3'. VLGR1 CT: 5'-GGAGUUUGAUGACCUGAUAtt-3'/5'-UA UCAGGUCAUCAAACUCCtg-3'. Knock-down cells were qualified by real-time quantitative RT-PCR using SYBR Green PCR Master Mix (Applied Biosystems), according to the manufacturer instructions, normalized to GAPDH transcript abundance, and compared with the scrambled siRNA. Real-time PCR primers were as follows: PCDH15(M): 5'-GAACTGGA GAGAGCGCAATGCATA-3' $/ 5^{\prime}$-GAGAACGT CCTTGCTGGGTTAGGCTG-3'; VLGR1 CT: 5'-CAGACCAGCCAGGCAAGCCCTGATTT-3'। 5'-GTTGTCACTGACACTGAGACCAGCAC-3'. After $48-72 \mathrm{~h}$, knock-down cells were processed for immunofluorescence and Western blot analysis. Specific bands were quantified using the software ImageJ 1.43 from the National Institutes of Health (http://imagej.nih.gov/ij). Immunoblots were stripped and reprobed with anti- $\beta$ actin, which was used as a loading control.

Tissue preparation and hair cell isolation Anesthetized animals were heart perfused with 5 $\mathrm{ml}$ of PBS, followed by $5 \mathrm{ml}$ of $4 \%$ paraformaldehyde (PFA) in $0.1 \mathrm{M}$ phosphate buffer as previously describe by Zallocchi et al. (2009). Microdissected cochleae were fixed in PFA 4\% for $3 \mathrm{~h}$ at $4^{\circ} \mathrm{C}$ and transferred to $30 \%$ sucrose in $0.1 \mathrm{~m}$ phosphate buffer overnight at $4^{\circ} \mathrm{C}$. Fixed tissue was mounted using OCT compound, frozen, and cut at $12 \mu \mathrm{m}$ for immunohistochemistry.

Hair cell isolation from P1 cochleae was performed according to Zallocchi et al. (2012). Briefly, cells were dissociated from organs of Corti with papain $0.5 \%$ for $25 \mathrm{~min}$ at room temperature, transferred to glass slides, fixed for 30 min with $4 \%$ PFA, and permeabilized for $10 \mathrm{~min}$ with $0.3 \%$ Triton X-100 (PBST).

Cell culture

Cultivation of UB/OC-1 was conducted as previously reported (Rivolta et al., 1998, 2002; Zallocchi et al., 2009, 2012), with noted exceptions. Briefly, cells were maintained in DMEM/F-12 medium (Invitrogen) sup- 

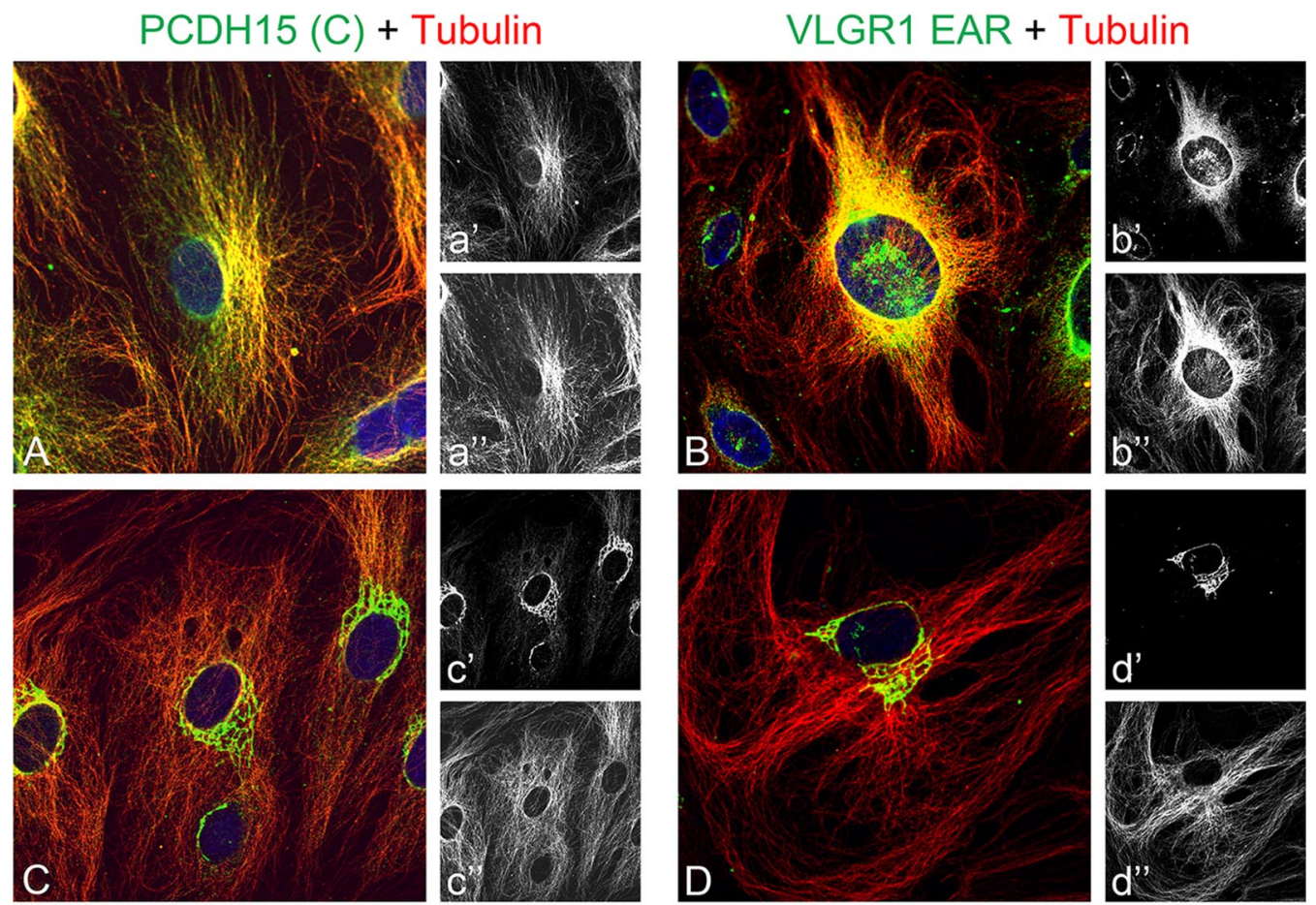

PCDH15 (M) + Tubulin
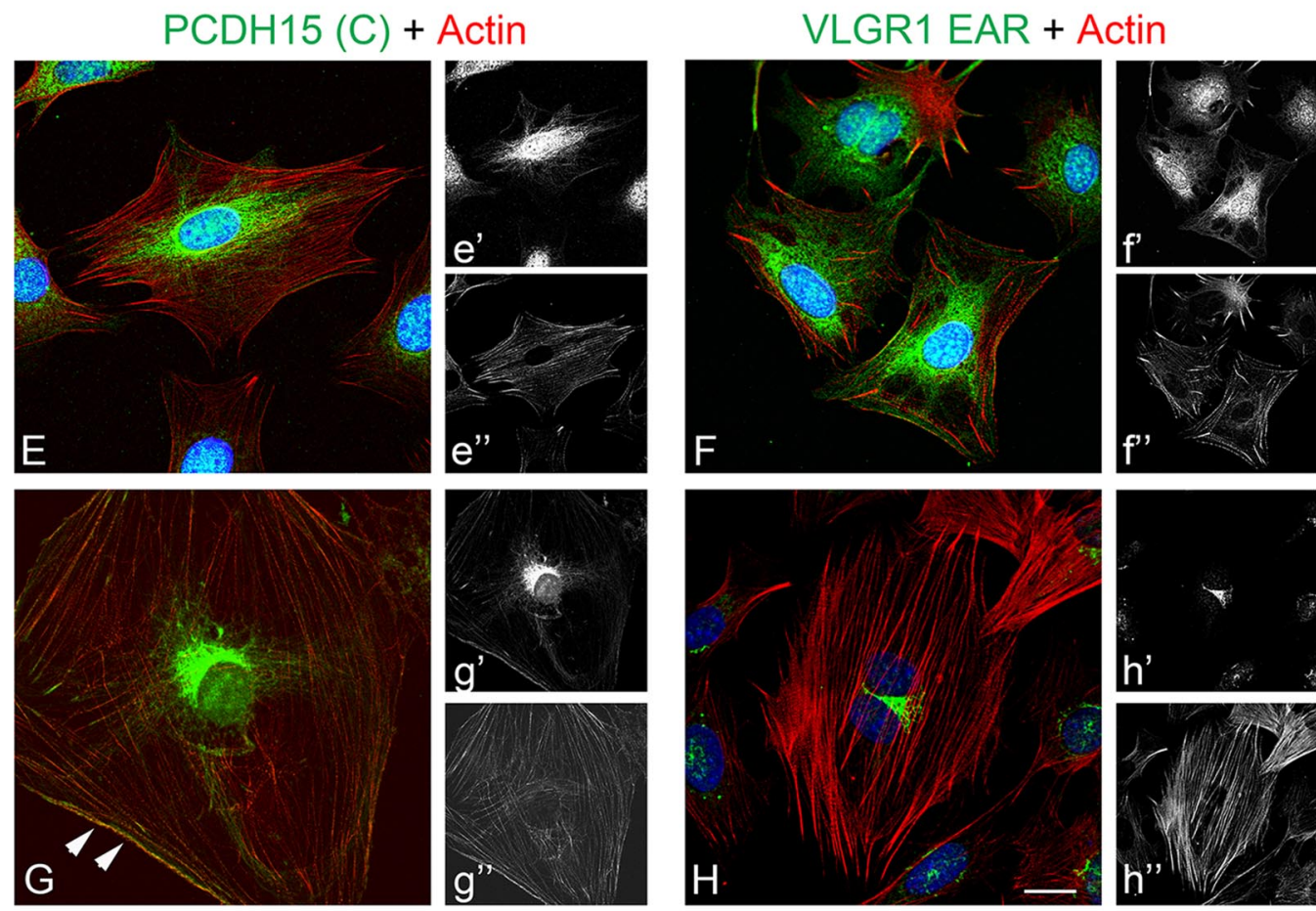

PCDH15 $(\mathrm{M})+$ Actin
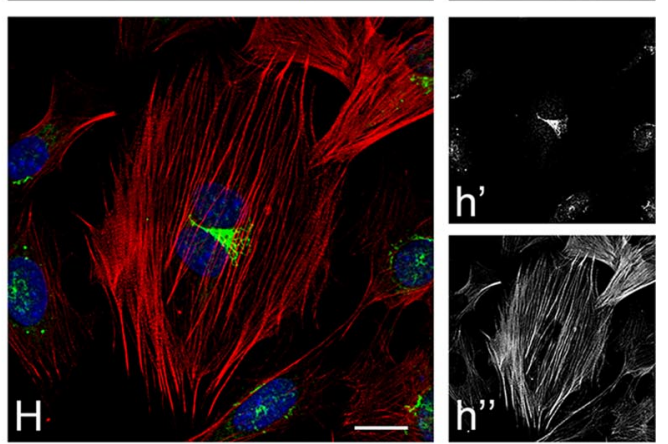

VLGR1 CT + Actin

Figure 3. Expression analysis of the Usher proteins in differentiated UB/OC-1 cells. Cells were immunostained for the different Usher proteins (green) and $\beta$-tubulin (red) or counter stained with phalloidin for F-actin (red). DAPI was used to stain the nucleus. $\boldsymbol{A}-\boldsymbol{H}$, Merged images. $\boldsymbol{a}^{\prime}-\boldsymbol{h}^{\prime}$, Usher protein immunostaining; $\boldsymbol{a}^{\prime \prime}-\boldsymbol{h}^{\prime \prime}$, cytoskeletal marker staining; $\boldsymbol{A}-\boldsymbol{a}^{\prime \prime}, \boldsymbol{E}-\boldsymbol{e}^{\prime \prime}, P C D H 15(C) ; \boldsymbol{B}-\boldsymbol{b}^{\prime \prime}$, $\boldsymbol{F}-\boldsymbol{f}^{\prime \prime}, \mathrm{VLGR1}$ EAR; $\boldsymbol{C}-\boldsymbol{c}^{\prime \prime}, \boldsymbol{G}-\boldsymbol{g}^{\prime \prime}$, PCDH15(M); $\boldsymbol{D}-\boldsymbol{d}^{\prime \prime}, \boldsymbol{H}-\boldsymbol{h}^{\prime \prime}, \mathrm{VLGR1}$ (T; $\boldsymbol{A}-\boldsymbol{d}^{\prime \prime}, \boldsymbol{\beta}$-tubulin immunostaining; $\boldsymbol{E}-\boldsymbol{h}^{\prime \prime}$, actin counterstaining. Arrowheads denote plasma membrane localization. Scale bar, $15 \mu \mathrm{m}$.

plemented with $5 \%$ fetal calf serum (FCS, Invitrogen), $100 \mathrm{U} / \mathrm{ml}$ penicillin, $0.1 \mathrm{mg} / \mathrm{ml}$ streptomycin, and $0.29 \mathrm{mg} / \mathrm{ml} \mathrm{L}$-glutamine (Invitrogen). To propagate them, cells were maintained at $33^{\circ} \mathrm{C}$ and the culture medium supplemented with $10 \mathrm{U} / \mathrm{ml}$ mouse recombinant $\gamma$-interferon (Calbiochem). Subconfluent cultures $(\sim 80 \%)$ were dissociated with
0.05\% trypsin, $0.02 \%$ EDTA (Invitrogen), and replated at 1:5. To induce differentiation, dissociated cells were grown in medium lacking $\gamma$-interferon and maintained at $37^{\circ} \mathrm{C}$ for at least $10 \mathrm{~d}$. Fully differentiated cells were used as a source of protein for further biochemical analysis or dissociated, plated onto poly-L-lysine coated microscope slides (VWR 
A

\begin{tabular}{ccc}
\hline PCDH15 $(\mathbf{C})+$ Tubulin $(\mathrm{n}=6)$ & $+0.82 \pm 0.09$ & $+0.37 \pm 0.02$ \\
\hline PCDH15(C) + Actin $(\mathrm{n}=4)$ & $\mathrm{I}$ & $+0.19 \pm 0.06$ \\
\hline VLGR1 EAR + Tubulin $(\mathrm{n}=2)$ & $+0.83 \pm 0.01$ & $+0.35 \pm 0.01$ \\
\hline VLGR1 EAR + Actin $(\mathrm{n}=5)$ & $\mathrm{I}$ & $+0.20 \pm 0.05$ \\
\hline PCDH15(M) + Tubulin $(\mathrm{n}=2)$ & $+0.60 \pm 0.02$ & $+0.29 \pm 0.01$ \\
\hline PCDH15(M) + Actin $(\mathrm{n}=2)$ & I & $+0.18 \pm 0.10$ \\
\hline VLGR1 CT + Tubulin $(\mathrm{n}=2)$ & I & $+0.17 \pm 0.02$ \\
\hline VLGR1 CT + Actin $(\mathrm{n}=6)$ & I & $+0.15 \pm 0.04$ \\
\hline
\end{tabular}

$\mathrm{B}$
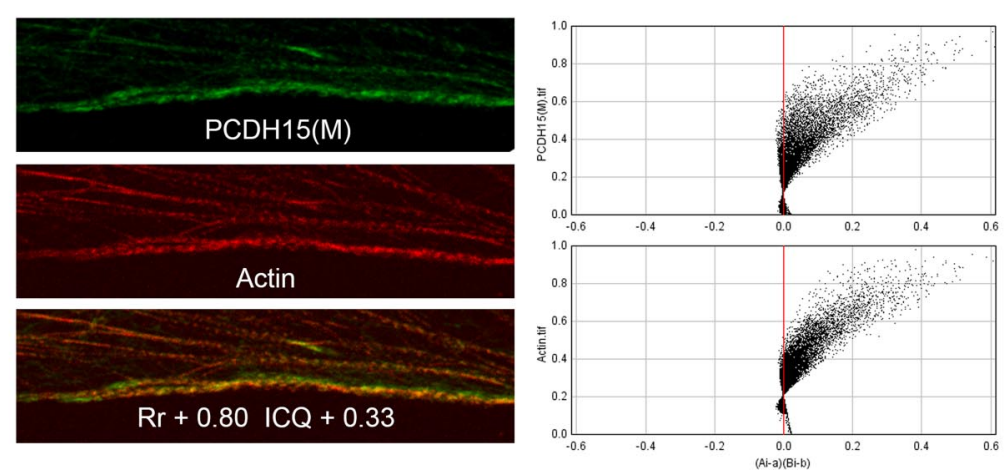

Figure 4. Quantitative colocalization analysis between the Usher proteins and the cytoskeletal proteins. $\boldsymbol{A}, \operatorname{Rr}$ and ICQ values. In the case of the Usher proteins with a filamentous-like distribution, the whole-cell area was used for the quantitative analysis. Colocalization indexes for PCDH15(M) and VLGR1 CT variants were calculated for the perinuclear region. I, Inconclusive results; $n$, number of independent experiments. $\boldsymbol{B}$, Left, High-magnification and colocalization coefficients for the area denoted with arrowheads in Figure 2. Right, ICA plots (intensity correlation analysis) for PCDH15(M) and actin at the cell surface of UB/0C-1 cells (left panels).

International), and maintained at $37^{\circ} \mathrm{C}$ for at least $24 \mathrm{~h}$ before immunofluorescence studies.

The cells attached to the slides were subsequently treated with brefel$\operatorname{din} \mathrm{A}$ (BrfA), $1 \mu \mathrm{g} / \mathrm{ml}$ for $30 \mathrm{~min}$ or A5 $50 \mu \mathrm{M}$ for $8 \mathrm{~h}$ (Calbiochem), and analyzed by confocal microscopy with the specific antibodies. Controls for drug specificity were also performed (data not shown).

\section{Immunofluorescence}

Cochlea. Fixed tissue was blocked for at least 30 min with PBST $0.3 \%$ containing $10 \%$ FCS and incubated with the primary antibodies in the same blocking solution. Primary antibody dilutions were 1:800 for antiPCDH15(C) and anti-VLGR1 EAR, 1:500 for anti-VLGR1 CT and antiPCDH15(M), 1:200 for anti-SNAP25, and 1:100 for goat anti-rab5A. Secondary antibodies were Alexa Fluor-conjugated antibodies (Invitrogen). In some experiments, 1:400 dilution of Alexa Fluor 594-conjugated phalloidin was included in the secondary antibody solution to label stereocilia. Controls with preimmune serum were done to test specificity of the antibodies (data not shown).

Isolated hair cells. Cells were incubated with the primary Usher antibodies 1:500 dilution in fish gelatin blocking solution (2\% FCS, $0.3 \%$ fish gelatin in PBS), overnight at $4^{\circ} \mathrm{C}$.

UB/OC-1 cells. Differentiated UB/OC-1 cells were grown and processed for confocal microscopy as described by Zallocchi et al. (2009). Dual immunostaining with rab5 was done in the absence of cell permeabilization. Primary antibody dilutions were 1:800 for anti-VLGR1 EAR, anti-VLGR1 CT, and anti-PCDH15(C), 1:500 for anti-PCDH15(M), $1: 300$ for anti-SNAP25 and mouse anti-rab5, and 1:200 for anti- $\beta$ tubulin and anti-GFP. Alexa Fluor 594-conjugated phalloidin was used at a dilution 1:200 to label microfilaments.

Cholera toxin labeling in live UB/OC-1 cells. The labeling of plasma membrane microdomains was done according to Lajoie et al. (2009) with some modifications. Briefly, cells attached to slides were incubated with 5 $\mu \mathrm{g} / \mathrm{ml}$ Cholera toxin (CTXB)-Alexa 568 (Invitrogen) for $30 \mathrm{~min}$ on ice to prevent internalization. Cells were fixed with $4 \%$ PFA for $30 \mathrm{~min}$ at room temperature and permeabilized for 7 min with PBST $0.3 \%$. After several washes with PBS, cells were incubated with anti-ribeye 1:100 dilution and the primary Usher antibodies.

\section{RabQ79L experiments}

Eight days differentiated UB /OC-1 cells grown in $100 \mathrm{~mm}^{2}$ dishes were electroporated with $10 \mu \mathrm{g}$ of pEGFP-C1 empty vector (EV-GFP, Clontech Laboratory) or GFP-Rab5Q79L (provided by J. Lippincott-Schwartz, National Institutes of Health, Bethesda, MD) (Nichols et al., 2001) in the presence of Gene Pulser Electroporation Buffer (Bio-Rad) and according to the manufacturer's instructions. Forty-eight hours following electroporation, cells were $4 \%$ PFA fixed and stained for GFP and VLGR1 CT.

\section{Confocal microscopy}

Slides were coverslipped using Vectashield mounting medium containing DAPI to counterstain the nuclei (Vector Labs) and confocal images captured using a Zeiss AxioPlan 2IF MOT microscope interfaced with a LSM510 META confocal imaging system, using a $63 \times$ NA:1.4 oil objective. Final figures were assembled using Adobe Photoshop and Illustrator software (Adobe Systems).

\section{Colocalization analysis}

Colocalization was analyzed using ImageJ 1.43 as previously described (Li et al., 2004; Grati and Kachar, 2011). Two different colocalization indexes were calculated. The $R r$ or Pearson's correlation coefficient for fluorescence images with values close to +1 for positive correlation and near to -1 for negative correlations. A value near 0 indicates no correlation, values between -0.5 and +0.5 do not allow any conclusions. The intensity correlation quotient or ICQ, described by Li et al. (2004), is based on the principle that if two proteins are forming a complex, their staining will vary in synchrony (dependence, $0<\mathrm{ICQ} \leq+0.5$ ), whereas if they are part of different structures or complexes their fluorescence staining will vary asynchronously (segregation, $0>\mathrm{ICQ} \geq-0.5$ ). Random staining intensities will result in an ICQ $\approx 0$. Intensity correlation analysis (ICA) plots derived from the ICQ algorithm can be generated for each color channel. The axes on the plots represent the Product of the Differences from the Mean (PDM) on the $x$-axis and the red or green intensity on the $y$-axis. A random distribution will generate a symmetrical hourglass shape scatter plot while plots for a dependent or segregated distribution will generate hourglass shapes markedly skewed toward positive or negative values, respectively.

\section{Velocity gradients}

Differentiated UB/OC-1 cells were grown to confluence and processed for sucrose velocity gradients as described before for the isolation of vesicular complexes, but adapted for cell culture (Deretic and Papermaster, 1991; Zallocchi et al., 2010). Briefly, two $150 \mathrm{~mm}^{2}$ dishes were washed three times with cold phosphate buffer, cells were scraped in a total volume of $7.5 \mathrm{ml}$ of sucrose buffer [10 mM Tris-Ac pH 7.4, $0.25 \mathrm{M}$ sucrose, $1 \mathrm{~mm} \mathrm{MgCl}_{2}$, and protease inhibitor cocktail (Sigma)]. The cells were homogenized, cleared by centrifugation, and the supernatant layered in a continuous $20-39 \% \mathrm{w} / \mathrm{v}$ sucrose gradient with a $49 \% \mathrm{w} / \mathrm{v}$ sucrose cushion. After $20 \mathrm{~h}$ of centrifugation at 22,000 rpm using a SW28 rotor (Beckman Coulter), 14 fractions $(2.75 \mathrm{ml}$ each) were collected from the bottom (fraction 1) to the top (fraction 14) of the gradient and analyzed by Western blot. Silver staining of polyacrylamide gels were run in parallel to corroborate the presence and intactness of protein in all the fractions and not only in the ones where we detect the Usher proteins (data not shown). Results are representative of at least three independent experiments. 
Sucrose gradient analysis of

TX-100-insoluble proteins

Equilibrium sucrose gradient centrifugation was performed according to Paladino et al. (2004) but adapted to smaller scale samples. Briefly, one $150 \mathrm{~mm}^{2}$ dish of confluent UB/ OC-1 cells was scraped and homogenized in TNE/1\%TX-100 buffer (Tris:HCl $25 \mathrm{~mm} \mathrm{pH}$ 7.5, $\mathrm{NaCl} 150 \mathrm{~mm}$, EDTA $5 \mathrm{~mm}$, and 1\% Triton $\mathrm{X}-100$ ). Cell suspension was brought to $40 \%$ sucrose and placed at the bottom of a $5-35 \%$ discontinuous sucrose gradient. Samples were centrifuged at $33,000 \mathrm{rpm}$ for $18.5 \mathrm{~h}$ in a TLS 55 swinging bucket rotor (Beckman Coulter) and 12 fractions were collected from the bottom of the tube (fraction 1). Samples were assessed for the presence of GM1 ganglioside by dot-blot with HRP-conjugated CTXB (Sigma) or TCAconcentrated and analyzed by immunoblot for the different Usher proteins.

\section{Immunoprecipitation studies}

Coimmunoprecipitation studies with SNAP25. $\mathrm{P} 1$ inner ear and $\mathrm{P} 3$ brain were homogenized in coimmunoprecipitation (co-IP) buffer (Tris: $\mathrm{HCl} 10 \mathrm{~mm}$ pH 7.4, $\mathrm{NaCl} 150 \mathrm{~mm}, \mathrm{MgCl}_{2} 0.5$ $\mathrm{mm}, \mathrm{CaCl}_{2} 0.5 \mathrm{~mm}$, and Brij 97 1\%) and used for interaction studies. Sixty microliters of a $50 \%$ slurry suspension of protein G-agarose beads (Sigma) were incubated overnight at $4^{\circ} \mathrm{C}$ with $3 \mu \mathrm{g}$ of mouse anti-SNAP25 or normal mouse serum. The antibody-conjugated beads were incubated overnight in the presence of protein lysates $(0.5 \mathrm{mg}$ for organ of Corti, $2 \mathrm{mg}$ for brain). After several washes, co-IPs were resuspended in sample buffer and analyzed by Western blotting.

Immunoprecipitation studies from UB/OC-1 membrane fractions. Differentiated UB/OC-1 cells were used for immunoprecipitation (IP) studies with the different Usher antibodies as described previously (Zallocchi et al., 2012). In brief, eight $150 \mathrm{~mm}^{2}$ confluent cultures were processed for the isolation of membranes as described by Le-Niculescu et al. (2005). Sixty microliters of a $50 \%$ slurry suspension of protein A Sepharose beads (Sigma) were incubated overnight at $4^{\circ} \mathrm{C}$ with $10 \mu \mathrm{l}$ of the specific antibody or normal rabbit serum. After two washes with $500 \mu \mathrm{l}$ of IP buffer (HEPES $25 \mathrm{~mm}$ $\mathrm{pH} 7.4, \mathrm{NaCl} 150 \mathrm{~mm}, \mathrm{Mg}_{2} \mathrm{Cl} 1 \mathrm{~mm}, \mathrm{NP}-40$ 1\%, and protease inhibitor cocktail), immunobeads were incubated overnight at $4^{\circ} \mathrm{C}$ in the presence of the membrane fraction. Immunobeads were then washed five times with IP buffer, resuspended in sample buffer, and used for Western blot analysis.

\section{Western blot}

Differentiated UB/OC-1 cells and P1 cochleae were homogenized in RIPA buffer ( $150 \mathrm{~mm} \mathrm{NaCl}, 50 \mathrm{~mm}$ Tris, 1 mm EDTA, 1\% NP-40, 0.5\% sodium deoxycholate, $0.1 \% \mathrm{SDS}, \mathrm{pH} 7.4$ ) containing protease inhibitors, cleared by centrifugation, and $20-30 \mu \mathrm{g}$ (cells) or 50-60 $\mu \mathrm{g}$ (cochleae) of protein used for Western blot analysis. Gradient (4-20\%, Invitrogen), $10 \%$ or $8 \%$ acrylamide gels were used to resolve the protein samples and immunoblots were conducted as previously described by Zallocchi et al. (2012). HRP-conjugated protein A (GE Healthcare Life Sciences) dilution 1:20,000 was used instead of secondary antibody to avoid or decrease cross-reactivity with the IgGs present in the tissue and tissue extracts used for IPs and co-IPs. Primary antibody dilutions were as follows: Usher antibodies 1:500; anti-SNAP25 1:500, anti-rab5A 1:200, and anti- $\beta$-actin $1: 2000$.
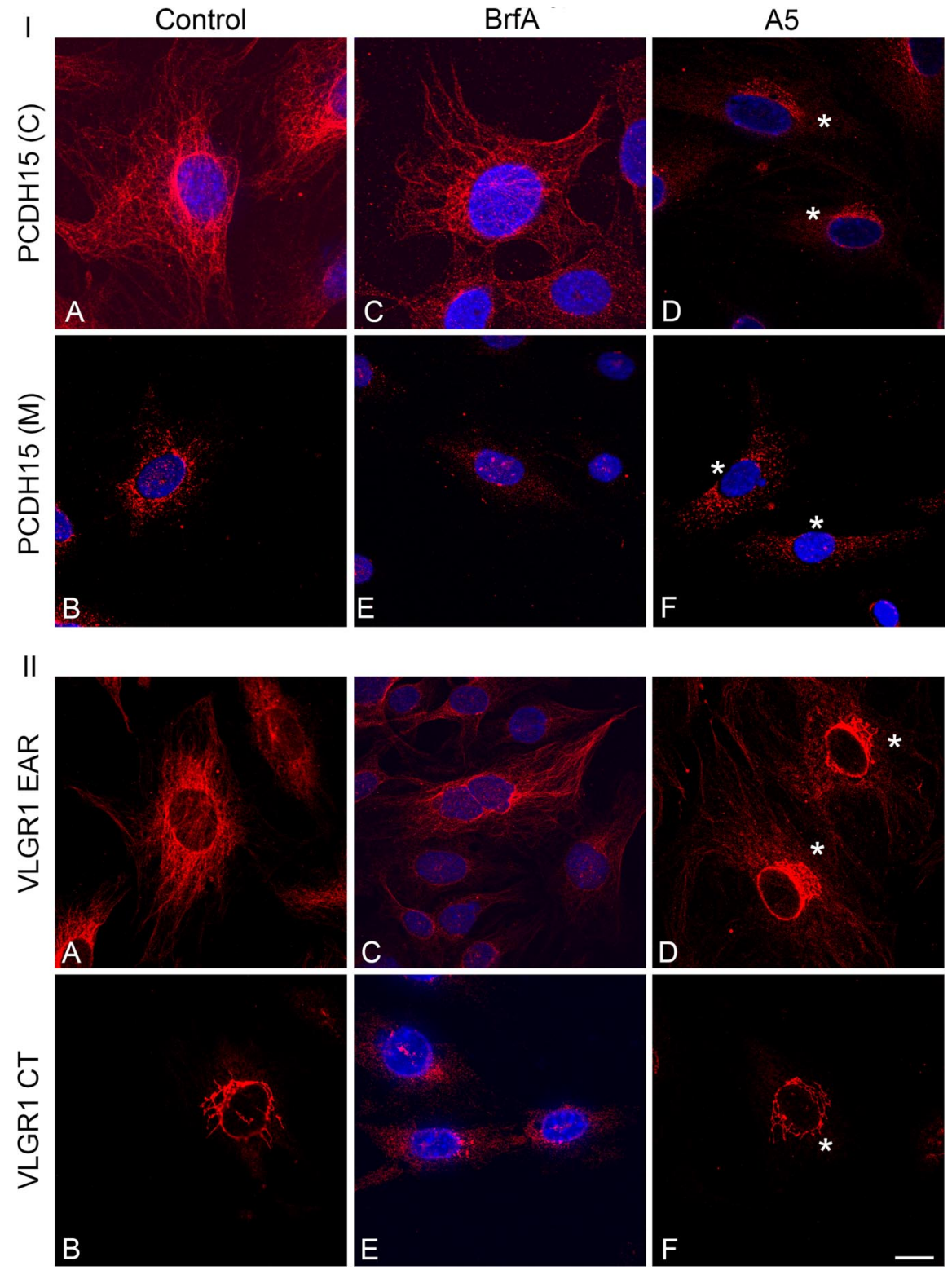

Figure 5. Immunofluorescence analysis of PCDH15 and VLGR1 in differentiated UB/OC-1 cells treated with the trafficking inhibitors brefeldin $A$ or $A 5$. Cells were incubated with vehicle $(\boldsymbol{A}, \boldsymbol{B})$, brefeldin $A(\operatorname{BrfA})(\boldsymbol{C}-\boldsymbol{E})$, or $\mathrm{A} 5(\boldsymbol{D}-\boldsymbol{F}) . \mathbf{I}: \boldsymbol{A}, \boldsymbol{C}, \boldsymbol{D}$, antiPCDH15(C). $\boldsymbol{B}, \boldsymbol{E}, \boldsymbol{F}$, Anti-PCDH15(M). II: $\boldsymbol{A}, \boldsymbol{C}, \boldsymbol{D}$, Anti-VLGR1 EAR. $\boldsymbol{B}, \boldsymbol{E}, \boldsymbol{F}$, Anti-VLGR1 CT. DAPI was used to stain the nucleus. Asterisks denote perinuclear distribution in treated cells. Scale bar, $15 \mu \mathrm{m}$.

\section{Results}

Determination of variant specificity for anti-PCDH15(M) and anti-VLGR1 CT

The specificity of anti-PCDH15(M) and anti-VLGR1 CT has been previously demonstrated through the use of Usher mutant mouse models and heterologous expression systems (Senften et al., 2006; McGee et al., 2006; Maerker et al., 2008). We further qualified these reagents to establish their isoform specificity in the mouse embryonic hair cell line UB/OC-1 that endogenously expresses many isoforms of all the known Usher proteins (Rivolta et al., 1998, 2002; Zallocchi et al., 2009, 2012) (our unpublished data). As previously shown for qualifying PCDH15(C) and VLGR1 EAR antibody specificity (Zallocchi et al., 2012), we transiently knocked down PCDH15 and VLGR1 transcripts with siRNAs targeted to a region within the immunogen sequence for anti-PCDH15(M) and anti-VLGR1 CT (Fig. $1 A$, double-headed 


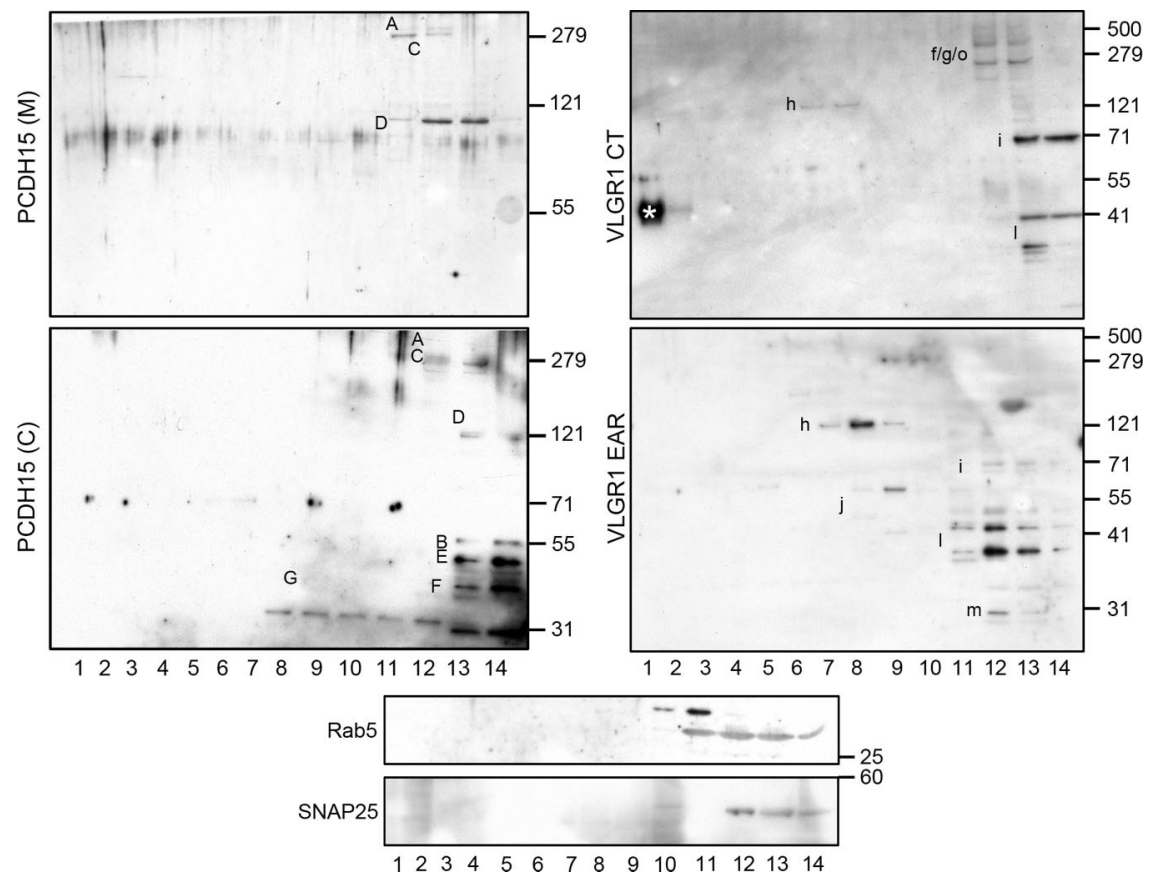

Figure 6. Biochemical characterization of Usher proteins from UB/OC-1 cells fractionated by velocity sedimentation on sucrose gradients. Left panels, Analysis of PCDH15 distribution following velocity sedimentation on sucrose density gradients. Fourteen samples were collected from the bottom (1) to the top (14) of the gradient and membranes were immunoblotted with antiPCDH15(M) (top) or anti-PCDH15(C) (bottom). Right panels, Analysis of VLGR1 distribution following velocity sedimentation on sucrose density gradients. Membranes were immunoblotted with anti-VLGR1 CT (top) or anti-VLGR1 EAR (bottom). Asterisk denotes some insoluble material for that particular experiment. Bottom middle panels, Sucrose density gradients were also used to analyze the distribution of rab5 and SNAP25. Molecular weight markers (kDa) are denoted to the right. The letters next to each band refer to specific variants according to pre-established designations (Ahmed et al., 2003, 2006, 2008; Reiners et al., 2005a; McMillan and White, 2004; Kazmierczak et al., 2007; Zallocchi et al., 2012).

arrows) (see Materials and Methods). Real-time quantitative RTPCR showed a $>50 \%$ reduction for these transcripts in the specific knock-down cells compared with the scrambled siRNA cells (data not shown). Immunocytochemistry studies also showed a decrease of the fluorescence signal in the specific knock downs (data not shown). Western blot analyses of these knock downs show a reduction of $52 \%$ to $91 \%$ for the PCDH15(M) variants and between $46 \%$ and $93 \%$ for the VLGR1 CT variants (Fig. $1 B$ ). PCDH15(M) antibody was raised against the terminal part of the cytoplasmic domain of PCDH15 CD1 (Fig. 1A) (Senften et al., 2006, Webb et al., 2011) and thus recognizes all the variants containing the immunogen region coded by exon 35, which itself can undergo incomplete splicing (Alagramam et al., 2007). We detected and specifically knocked down four previously described PCDH15(M) variants from UB/OC-1 lysates (Fig. $1 B$ ) and two novel variants (asterisk). In the case of VLGR1 CT, this antibody was raised against the last portion of the mouse C-terminal domain (Fig. $1 A$ ) and, thus, recognizes all the variants containing this domain. By using specific siRNAs we were able to knock down four different VLGR1 variants (Fig. $1 B$ ). Although we have already demonstrated that $V \lg r l l$ is a specific VLGR1 variant recognized by the anti-VLGR1 EAR antibody preparation (Zallocchi et al., 2012), we did not observe any reduction when using a different set of siRNA sequences and anti-VLGR1 CT as the blotting antibody. This negative result is probably due to the absence of that particular complementary sequence from Vlgr 1 .

We did not characterize these Usher protein bands at the transcript level. Since they can arise from either alternative splicing of the full-length transcripts or from translational modifications of the different known protein isoforms (i.e., specific proteolysis, lipidation, glycosylation, etc.), we henceforth refer to them as variants. Overall, the reduction in abundance observed for the specific knock downs (KD) compared with the scrambled $(\mathrm{Ctl})$ transfected cells (Fig. $1 B$ ) demonstrates the specificity of the bands detected by these antibodies on Western blots.

Differential expression of PCDH15 and VLGR1 protein variants in immature mouse cochlea and hair cells

The comparative analysis of the Usher variants in UB/OC-1 cells and P1 mouse cochleae demonstrate there is common as well as RNA source-specific bands detected by the Usher antibodies (McMillan and White, 2004; Reiners et al., 2006; Ahmed et al., 2006; Kazmierczak et al., 2007; Zallocchi et al., 2012). Figure 1C (left panels) shows there are six common variants recognized by anti-PCDH15(C) and anti-PCDH15(M) in UB/OC-1 and cochlea lysates. Both antibodies detect the full-length PCDH15 (variant "A") (Ahmed et al., 2003, 2006; Reiners et al., 2005a) and five additional variants: variant "C" at $250 \mathrm{kDa}$ (Ahmed et al., 2006; Zallocchi et al., 2012), variant "D" at 120 $\mathrm{kDa}$ (Zallocchi et al., 2012), the bands between the $71 \mathrm{kDa}$ and $50 \mathrm{kDa}$ markers (Fig. $1 C$, asterisk), variant "B" at $\sim 50 \mathrm{kDa}$ (Ahmed et al., 2003; Reiners et al., 2005a), and at $<50 \mathrm{kDa}$, variant "E" (Zallocchi et al., 2012). Because these five variants are being recognized by both PCDH15 antibodies (Fig. 1A), they likely contain the complete cytoplasmic domain (Fig. $1 D$ ). There are three variants recognized exclusively by antiPCDH15(C): variants "F" and " $\mathrm{H}$ " detected only in UB/OC-1 cells and variant "G" present in both $\mathrm{P} 1$ cochlea and UB/OC-1 cells.

The analysis of VLGR1 expression in cochleae and UB/OC-1 cells (Fig. $1 C$, right) shows there are again common variants detected by both antibody preparations, which suggests they contain the EAR/EPTP and cytoplasmic domains (Fig. 1A). AntiVLGR1 EAR and anti-VLGR1 CT detect the full-length VLGR1 (Vlgr $1 b$ at $690 \mathrm{kDa}$ ) (McMillan and White, 2004) as well as V/grlf/g/o (several bands near the $279 \mathrm{kDa}$ marker), Vlgrl $h$ at $120 \mathrm{kDa}, V$ lgr1 $i$ at $\sim 70 \mathrm{kDa}$, and $V \lg r 1 \mathrm{l}$ at $\sim 40 \mathrm{kDa}$. In addition, the EAR domain antibody reacts with three smaller variants, $\operatorname{Vgr} 1 j$ at $\sim 50 \mathrm{kDa}$ and Vlgr Im and Vlgr In around the $31 \mathrm{kDa}$ marker. Because these three variants are being recognized by anti-VLGR1 EAR exclusively, they contain the EAR/EPTP domain but not the cytoplasmic region used to develop anti-VLGR1 CT.

The differences in the pattern of expression between $\mathrm{P} 1$ cochleae and UB/OC-1 cells for PCDH15 and VLGR1 may, very likely, represent differences in protein abundance. Most of these PCDH15 and VLGR1 variants have already been described at the protein and/or transcript level by different groups (Ahmed et al., 2003, 2006, 2008; Reiners et al., 2005a; McMillan and White, 2004; Kazmierczak et al., 2007; Zallocchi et al., 2012). Preliminary results from our laboratory suggest the existence of novel alternative spliced PCDH15 CD1 transcripts expressed in P1 mouse inner ear (data not shown). 
Figure $1 D$ summarizes the results presented in Figure $1 C$, including the putative protein domains present in each variant according to the antibody-antigen recognition pattern.

Because PCDH15 and VLGR1 are localized at the apical and basal aspects of cochlear hair cells (van Wijk et al., 2006; Yagi et al., 2007; Zallocchi et al., 2012), we explored whether distinct variants are present in these locations using the two different antibody preparations for each of these Usher proteins (Fig. 1). As we previously observed in mouse cochlea (Zallocchi et al., 2012), the subset of variants recognize by anti-PCDH15(C) and antiVLRG1 EAR are present at the stereocilia level (Fig. 2A,B,E,F,I,K, asterisks) and also at the base of inner and outer hair cells and in the afferent fibers that innervate them (arrowheads). The PCDH15 variants detected by anti-PCDH15(M) are present at the apical aspect of cochlear hair cells (Fig. 2C,D, J, asterisks) and at the neuronal terminals (arrowheads). No expression was detected for these variants at the base of the hair cells (Fig. $2 J$ ).

The apical expression of the full-length PCDH15 as well as its role in tip link formation is well established (Seiler et al., 2005; Senften et al., 2006; Alagramam et al., 2007, 2011; Kazmierczak et al., 2007; Lelli et al., 2010; Webb et a., 2011). The fact that anti-PCDH15(M) does not show any basal immunoreactivity in isolated cochlear hair cells (Fig. $2 J$ ) suggests that the five additional variants ("C," " $\mathrm{D}$," "*, " "B," and "E," Fig. 1C) shared by both antibody preparations may be exclusively present at the apical aspect of the hair cells. An alternative explanation is that they are present both apically and postsynaptically at the neuronal terminals, but not at the basal aspect of cochlear hair cells. As for the two additional variants "F" and "H" (Fig. 1C), recognized exclusively by anti-PCDH15(C), they may represent low abundance variants (we only detect them in $\mathrm{UB} / \mathrm{OC}-1$ lysates), present at the synapses, as is the case for variant "G" (Zallocchi et al., 2012) or basal and apical PCDH15 variants.

Anti-VLGR1 CT reacts only with VLGR1 variants present at the apical aspect of the hair cells, no basal or neuronal expression was observed in either cochlea cross-sections or isolated hair cells (Fig. 2G, $H, L$ ).

Little information is currently available regarding the VLGR1 variants present at the hair bundle. Our previous studies demonstrated the expression of the full-length and two additional variants (Vlgrlf/g/o and Vlgrlm) at the synapses of cochlear hair cells (Zallocchi et al., 2012). The fact that VLGR1 CT does not show any immunoreactivity at the base of the hair cells but still reacts with some of the synaptic variants (Vlgr $1 \mathrm{f} / g / o$ ) in our Western blots (Fig. $1 C$ ) is likely due to epitope masking or inaccessibility after PFA fixation.

Summarizing, the results show that distinct variants of PCDH15 and VLGR1 are present at the basal and apical poles of cochlear hair cells, suggesting a regulated differential intracellular trafficking (Fig. 2, table): Specific pools of variants recognized by
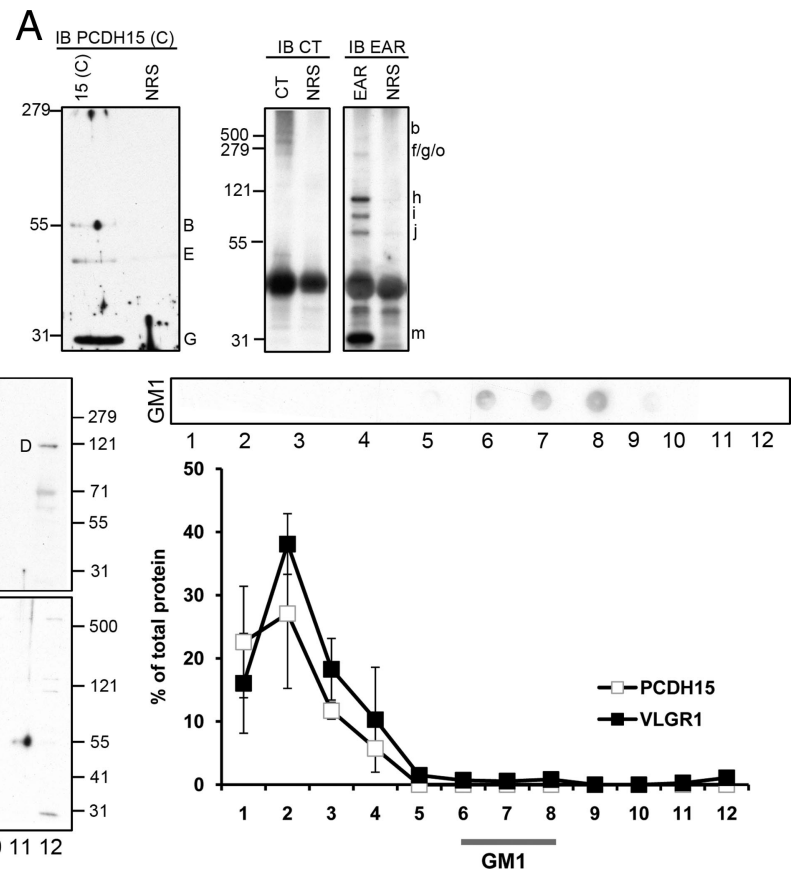

GM1

Association of Usher variants with membrane domains. A, Membrane fractions from UB/OC-1 cells were immuno-

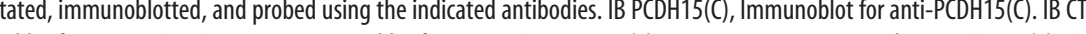
列 antibodies. Top left, Membranes were immunoblotted with anti-PCDH15(C). Bottom left, Membranes were immunoblotted with each fraction was used for dot-blot to reveal GM1-enriched microdomains. Bottom right, Distribution curves are the average of four independent experiments (SEs bars and positioning of the DRM fraction are indicated).

anti-PCDH15(C) and by anti-VLGR1 EAR are present in the stereocilia (ST) and basal membrane (BM) while the variants recognize by anti-PCDH15(M) and anti-VLGR1 CT are present primarily in the stereocilia (ST). Postsynaptic expression is also observed for variants recognize by anti-PCDH15(C), antiPCDH15(M), and anti-VLGR1 EAR (NT).

A similar analysis was performed in UB/OC-1 cells. Figure 3 shows a differential pattern of immunostaining for these antibodies, suggesting that distinct variants are being recognized by the different antibody preparations. PCDH15(C) and VLGR1 EAR antibodies show a filamentous-like immunostaining that colocalized with microtubules (Fig. $3 A-b$ ") but not with microfilaments (Fig. $3 E-f^{\prime \prime}$ ). The variants recognized by $\mathrm{PCDH15}(\mathrm{M})$ and VLGR1 CT antibodies present a prominent perinuclear immunostaining and poor colocalization with both cytoskeleton markers (Fig. 3C- $d$ " and $G-h$ "). However, at the cell surface there is a prominent colocalization between the actin cytoskeleton and the PCDH15(M) variants (Fig. 4).

The differential expression in UB/OC-1 cells parallels that observed in P1 mouse cochlea, where the "basal" variants detected by anti-PCDH15(C) and anti-VLGR1 EAR present a filamentous-like distribution and the "apical" variants detected by anti-PCDH15(M) and anti-VLGR1 CT a perinuclear localization.

These observations suggest that the same or similar variants are being recognized by the Usher antibodies both in the cochlea and in the hair cell line, making the latter a good system to study the trafficking and distribution of specific Usher variants.

Quantitative analysis of the relationship between the Usher proteins and the cytoskeletal markers confirm what we observed 

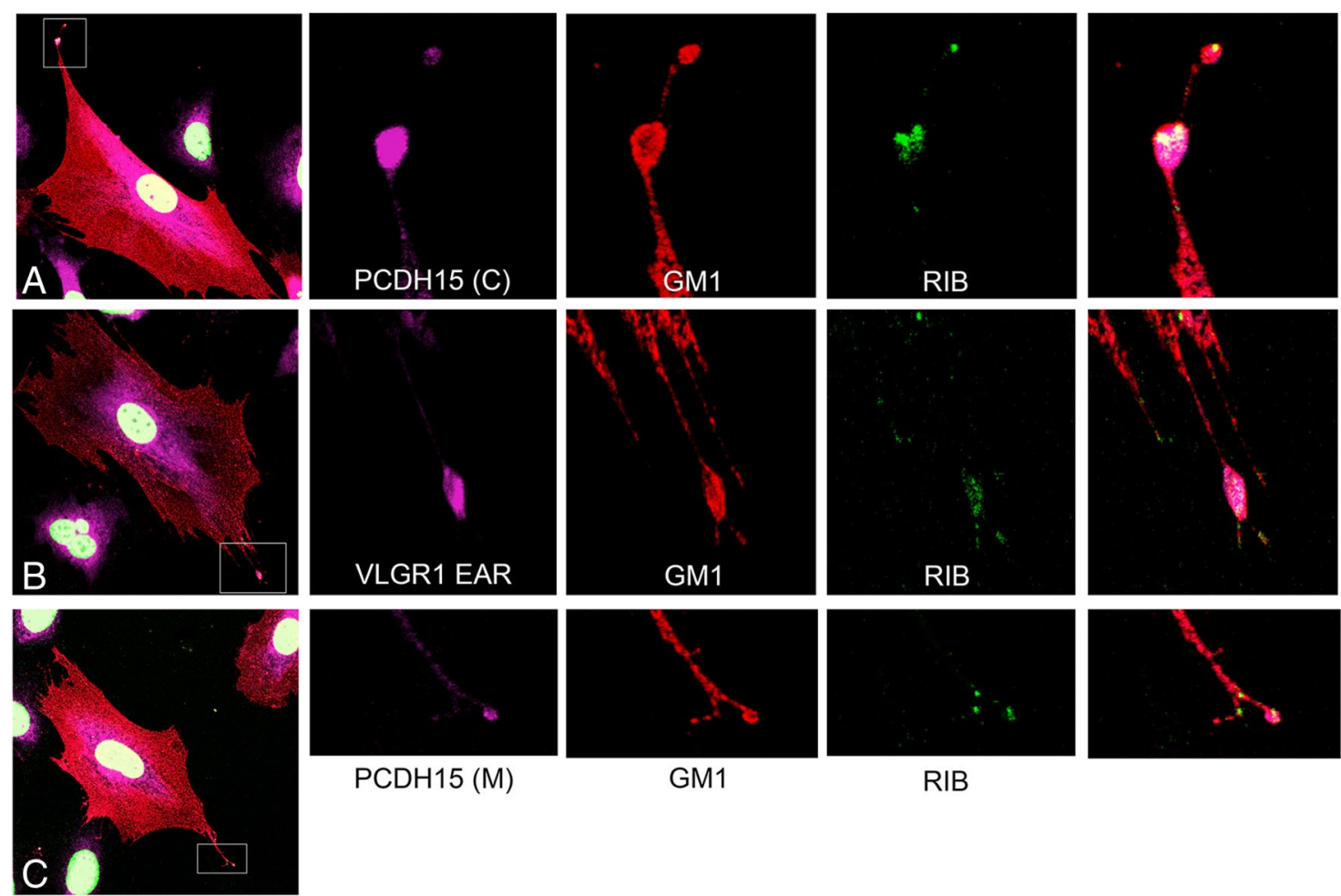

$\mathrm{PCDH} 15(\mathrm{M})$
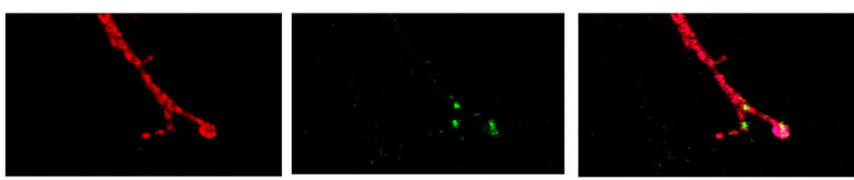

GM1

RIB
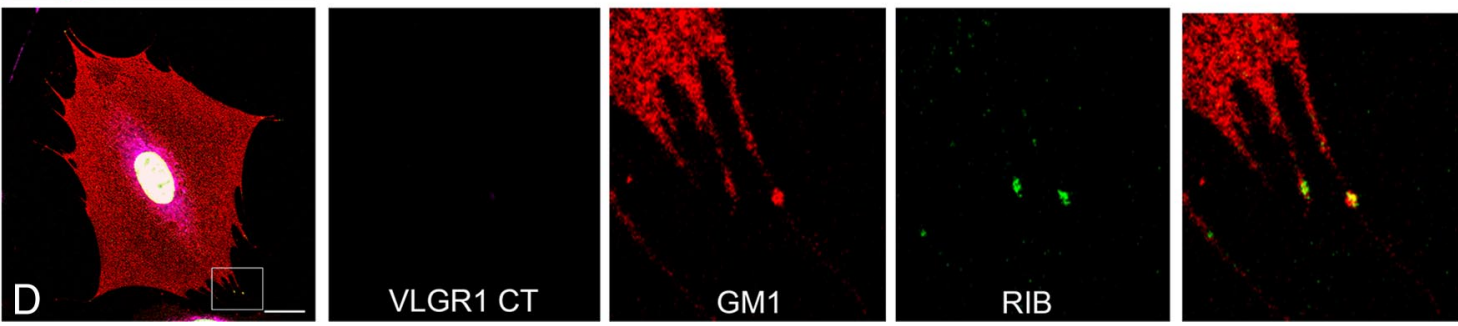

Figure 8. Usher protein colocalization with membrane microdomains and ribeye at the cell filopodia. Live UB/0C-1 cells grown on slides were labeled with Alexa 568-conjugated CTXB, fixed in PFA, and immunolabeled using the indicated anti-Usher protein antibodies (magenta) and anti-ribeye (green). Note that the Usher antibodies do not react as well as with acetone fixed cells and that anti-ribeye recognizes both isoforms, the transcription factor (nucleus staining), and the presynaptic marker (filopodia's tip staining). A, PCDH15(C) + GM1 + ribeye. B, VLGR1 EAR + GM1 + ribeye. C, PCDH15(M) + GM1 + ribeye. D, VLGR1 CT + GM1 + ribeye. High-magnification images correspond to the framed areas in $\boldsymbol{A}-\boldsymbol{D}$. Scale bar, $20 \mu \mathrm{m}$.

by dual confocal immunostaining (Fig. $4 A$ ). There is a strong association between tubulin and the variants detected by antiPCDH15(C) and anti-VLGR1 EAR. Pearson's values $(R r)$ are +0.82 and +0.83 for PCDH15 and VLGR1 respectively, while the ICQs (intensity correlation quotient, see Material and Methods) are +0.37 and +0.35 . Conversely, a weak association exists between these Usher variants and microfilaments. At the perinuclear region, where PCDH15(M) and VLGR1 CT are present, the colocalization with the cytoskeletal markers is weak or inconclusive in the case of Pearson's values $(I)$. Similar ICQs were obtained between actin and PCDH15(C) or PCDH15(M) (Fig. 4A), suggesting these are the shared apical actin-bound variants recognized by both antibody preparations. PCDH15(M) variants also localize with tubulin in UB/OC-1 cells, resulting in weak colocalization coefficients compared with PCDH15(C) variants. However, PCDH15(M) colocalization indexes show a strong association with cortical actin (Fig. 4B). ICA plots (see Materials and Methods) for colocalization values between PCDH15(M) and actin (Fig. $4 B, x-y$ graphs) generate hourglass figures that are skewed to the positive values demonstrating a dependent distribution at the cell surface for both proteins.
Table 1. Colocalization indexes between GM1-positive membrane microdomains and the Usher proteins

\begin{tabular}{|c|c|c|c|c|}
\hline & \multicolumn{2}{|l|}{ P1 cochlea } & \multicolumn{2}{|l|}{ UB/OC-1 } \\
\hline & $R r$ & ICQ & Rr & ICQ \\
\hline $\mathrm{PCDH15(C)} \mathrm{+} \mathrm{GM1}$ & $+0.53 \pm 0.10$ & $+0.24 \pm 0.03$ & $+0.73 \pm 0.04$ & $+0.39 \pm 0.08$ \\
\hline VLGR1EAR + GM1 & I & $+0.24 \pm 0.04$ & $+0.74 \pm 0.14$ & $+0.43 \pm 0.02$ \\
\hline PCDH15(M) + GM1 & I & $+0.23 \pm 0.02$ & $+0.67 \pm 0.11$ & $+0.36 \pm 0.09$ \\
\hline VLGR1 CT + GM1 & ND & ND & ND & ND \\
\hline
\end{tabular}

The basal region of the inner hair cells in $\mathrm{P} 1$ cochlea and the cell filopodia in UB/OC-1 cells were used to obtain the colocalization indexes. I, Inconclusive; ND, not determined. Four to sixindependent experiments were performed for P1 cochleae and three for UB/OC -1 cells.

\section{Specific variants of PCDH15 and VLGR1 are present in} distinct vesicular subpools

Because the Usher proteins are trafficked to opposite poles in hair cells and photoreceptors, a vesicular association for some of these variants has been suggested (Maerker et al., 2008; Zallocchi et al., 2009, 2010). To address whether distinct pools of vesicles are trafficking Usher proteins, we treated UB/OC-1 cells with different vesicular trafficking inhibitors. BrfA is an inhibitor of the ADP-Arf1, which is required for the formation of transport vesicles from Golgi membranes (Tsai et al., 1993; Duijsings et al., 2009), and A5 is a small molecule inhibitor of post-trans-Golgi 
vesicle transport that blocks the activity of AP-1 (Duncan et al., 2007). Figure 5 shows the redistribution pattern of the Usher proteins following drug treatment. BrfA specifically disrupts the distribution of the variants with a perinuclear immunostaining (Fig. 5E). In contrast, A5 disrupts the distribution of the variants presenting a filamentous-like immunolocalization pattern (Fig. 5D). The incubation with A5 reveals that there is also perinuclear immunostaining for the variants recognized by anti-PCDH15(C) and anti-VLGR1 EAR. This perinuclear immunostaining may be due to a reorganization of the "basal variants" from a filamentous to a perinuclear pattern after drug treatment. An alternative explanation is the masking of the perinuclear pattern by the more robust filamentous immunostaining in untreated cells versus A5-treated cells. If the latter is indeed the case, the perinuclear immunoreactivity may correspond to the subgroup of variants detected at the apical aspect of the hair cells (Fig. 2), which is consistent with the observation that these antibodies react to Usher proteins at both apical and basal poles of cochlear hair cells.

There is a correlation between the variants that localize to the stereocilia and those associated to Arf1-positive Golgi vesicles in UB/OC-1 cells. Likewise, a correlation also exists between the variants associated to the post-trans-Golgi compartment in UB/OC-1 cells and the ones detected at the basal aspect of the hair cells. Together, these results argue in favor of at least two distinct vesicular subpools differentially trafficked to either the basal or apical poles in cochlear hair cells.

The vesicular nature of the Usher variants was also addressed biochemically, by sucrose density velocity gradient experiments using UB/OC-1 cell extracts. This approach was previously described for the isolation of vesicular complexes from frog photoreceptors (Deretic and Papermaster, 1991), and applied by our group to the characterization of Usher protein complexes in tracheal epithelial cells (Zallocchi et al., 2010). Figure 6 shows there are two groups of Usher variants sedimenting into distinct fractions. The first group of PCDH15 and VLGR1 variants cosediments between fractions 11 and 14, at the top of the gradient (buoyant fraction), and the second group cofractionates toward the middle of the gradient (fractions 7-9). PCDH15 "A," "C," and "D," detected with both antibodies, sediment to the top fractions (left panels). Variants "B" and "E," although recognized by both antibodies in total protein lysates, are only detected by anti-PCDH15(C) after sucrose gradient fractionation. These two variants, together with " $G$ " and " $F$," specific tion. Scale bar, $5 \mu \mathrm{m}$.
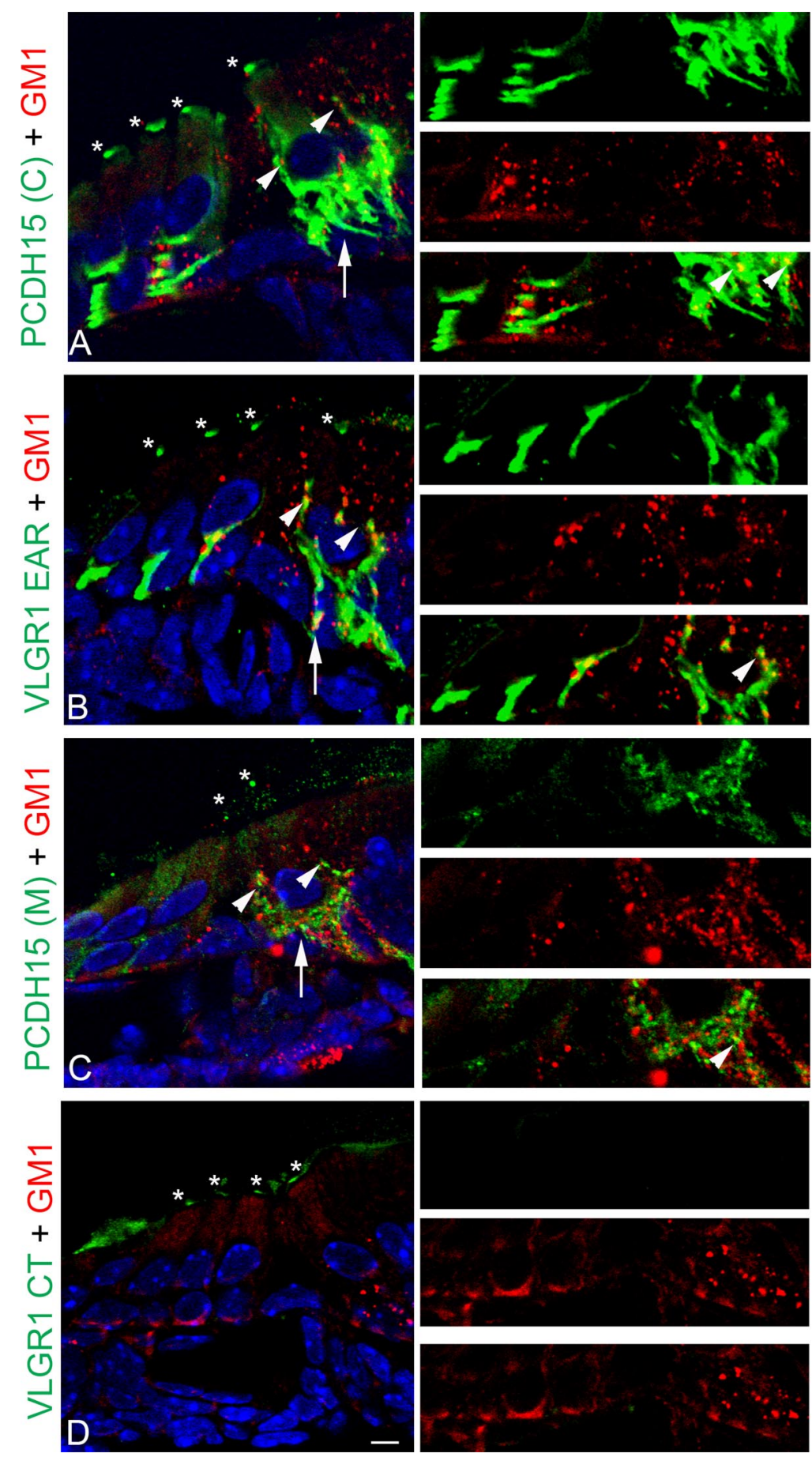

Figure 9. Partial colocalization of GM1-microdomains with the Usher proteins at the basal aspect of the hair cells in P1 cochlea. P1 cochlea cross-sections were double labeled for the Usher proteins (green) and GM1-DRMs (red). A, PCDH15(C) + GM1. B, VLGR1 EAR + GM1.C, PCDH15(M) + GM1.D, VLGR1 CT + GM1. High magnification of the basal regions is shown to the right. Asterisks denote apical expression of the Usher proteins. Arrowheads denote the presence of GM1-DRMs along the basolateral membrane. Arrows denote the presence of postsynaptic microdomains. Arrowheads in high-magnification images show points of colocaliza-

for anti-PCDH15(C) (Fig. 1C) (Zallocchi et al., 2012), also cosediment in the buoyant fraction. Only one variant, "G," detected by anti-PCDH15(C) sediment toward the middle of the gradient between fractions 7 and 9 (one of the bands forming a doublet at $31 \mathrm{kDa})$.

The velocity gradient analysis of VLGR1 (Fig. 6, right panels) show two common variants, Vlgrli and Vlgrll (doublet), cosedi- 

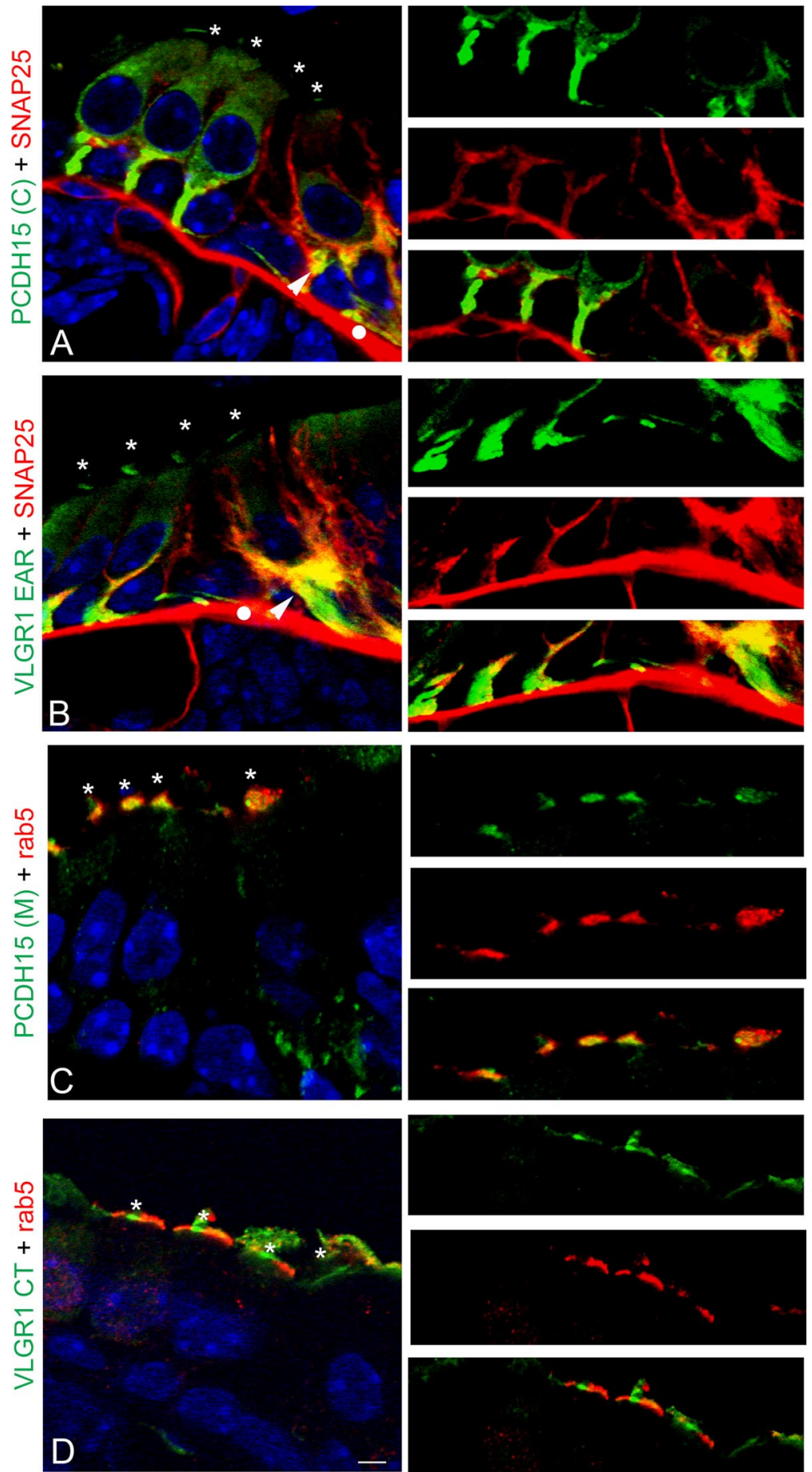

Figure 10. Colocalization analysis of the Usher proteins with basal and apical vesicular markers in P1 cochlea. P1 cochlea cross-sections were double immunostained for the Usher proteins (green) and the vesicular markers (red). $A, P C D H 15(C)+$ SNAP25. B, VLGR1 EAR + SNAP25.C, PCDH15(M) + rab5. D, VLGR1 CT + rab5. High magnification of the basal $(\boldsymbol{A}, \boldsymbol{B})$ or apical $(\boldsymbol{C}$, $D$ ) regions is shown to the right. Asterisks denote apical expression of the Usher proteins. Arrowheads denote colocalization of SNAP25 and Usher proteins at the base of the hair cells. White dots denote nonspecific staining of the anti-mouse secondary antibody. Scale bar, $6 \mu \mathrm{m}$.

menting in the top fractions while Vlgr $1 \mathrm{~h}$, also common to both antibodies, migrates toward the middle of the gradient (fractions 7-9). Vlgrlf/g/o sediments into the buoyant fraction. Although this variant reacts with both antibody preparations (Fig. 1), here we only detect it in VLGR1 CT immunoblots. Vlgrlj cosediments toward the middle of the gradient with Vlgr $1 h$. The small Vlgrlm variant, specific for anti-VLGR1 EAR, sediments into the buoyant fraction as do most of the variants.

Although we cannot completely rule out the possibility that some of the Usher variants from the complex may have dissociated due to the long centrifugation times, we feel this is unlikely, given that this sedimentation pattern was observed in several replicate experiments.

It is notable that we were unable to detect all the PCDH15 and VLGR1 variants present in UB/OC-1 cells (Fig. 1). This is likely due to their low abundance following the dilution of the sample after the sucrose fractionation.

The velocity gradient results reinforce the notion that at least two different complexes exist with distinct biochemical properties (i.e., different number of interacting proteins, size, and lipid composition, etc.) that may account for the distinct sedimentation velocities. The very different band sizes cofractionating in the detergent-free sucrose gradient, especially for the variants sedimenting into the top fractions, is consistent with a vesicular or membrane association (Deretic and $\mathrm{Pa}$ permaster;, 1991; Zallocchi et al., 2010).

Structural analysis of the full-length PCDH15 and VLGR1 suggests the presence of one and seven putative transmembrane domains, respectively (Petit, 2001; Reiners et al., 2005b, 2006; Kremer et al., 2006). To address whether some of the variants containing these domains may be bound to plasma or intracellular membranes, we performed immunoprecipitation studies from UB/OC-1 membrane-enriched fractions. Figure $7 A$ shows one of these experiments in which anti-PCDH15(C) immunoprecipitates variants " $\mathrm{B}$," "E," and the synaptic variant "G" (Zallocchi et al., 2012), while the VLGR1 antibodies immunoprecipitate the full-length VLGR1 (Vlgr1b), Vlgrlf/g/o, Vlgrl $h$, Vlgrli, Vlgrli, and the synaptic variant Vlgrlm (Zallocchi et al., 2012). These results demonstrate not only that these variants are associated to membranes but also further confirm the specificity of some of the bands detected by the antibodies.

The immunoprecipitation with antiPCDH15(M) did not show any specific band, which may suggest that we did not use optimal immunoprecipitation conditions for that particular antibody or that the antibody does not perform well for immunoprecipitation assays.

Characterization of the apical and basal vesicular subpools It has been suggested that sphingolipid (i.e., ganglioside GM1) and cholesterol-rich microdomains are involved in membrane signaling and trafficking of apical vesicles through their capacity 
to specifically partition certain types of lipids and proteins ( $\mathrm{Si}$ mons and Ikonen, 1997; Brown and London, 1998; Paladino et al., 2004, 2008; Sato et al., 2011). Studies in lower vertebrates demonstrated a high lipid order in the apical surfaces of polarized epithelia compared with the basolateral membranes (Owen et al., 2010). HEK293 cells stably transfected with clarin-1 showed an enrichment of this Usher protein in detergent resistant membranes (DRMs) (Tian et al., 2009). Based on these observations we aimed to address whether there is an association between the Usher vesicular complexes and membrane microdomains (Fig. $7 B)$. DRMs can be isolated by extraction with a nonionic detergent at $4^{\circ} \mathrm{C}$ followed by centrifugation to equilibrium on discontinuous sucrose density gradients (Brown and Rose, 1992; Paladino et al., 2004, 2008). Through performing these experiments we found that only a small fraction $(\sim 2 \%)$ of the VLGR1 variants (Vlgr1b and Vlgr1m, both synaptic) (Zallocchi et al., 2012) floated to the DRM-GM1 fraction. The majority of the bands were enriched in the fractions with higher isopycnic density (fractions 1-4) while only the tail of the gradient overlapped with the fractions in which the DRMs were recovered (fractions $6-8)$.

A second approach was also used to study the possible association of Usher proteins and membrane microdomains: Live UB/ OC-1 cells were stained with Alexa-conjugated cholera toxin followed by PFA-fixation and immunostaining for the different Usher proteins and the presynaptic marker ribeye (Sendin et al., 2007). Figure 8 shows colocalization between the membrane microdomains and PCDH15 or VLGR1 EAR variants at the tip of the cell filopodia where ribeye is localized (Fig. $8 A-C$, framed areas and magnified images). Pearson's and ICQ values confirm the existence of an association between membrane GM1-positive microdomains and the Usher proteins at the cell filopodia (Table $1)$. No colocalization is observed between the membrane microdomains and the variants recognize by the VLGR1 CT antibody (Fig. 8D).

A similar analysis in P1 cochleae show partial colocalization between the membrane microdomains and the Usher variants that are expressed by both hair cells ("basal variants") and afferent terminals (Fig. 9). GM1-positive microdomains are present at both the hair cell basolateral membrane (arrowheads) and the neuronal terminals (arrows). Although Pearson's values are inconclusive, at least for VLGR1 EAR and PCDH15(M) variants, the positive ICQ values show dependency in the distribution between the basal Usher proteins and membrane microdomains (Table 1). Anti-VLGR1 CT, which reacts with apical variants, does not show any localization or any association with membrane microdomains.

Overall, Figures 7-9 suggest there is a small fraction of the Usher variants that show some association with GM1-positive microdomains in mouse cochlea and at the cell filopodia in UB/ OC- 1 cells. For PCDH15, we did not observe cosedimentation with GM1 in sucrose velocity gradients, but still we observed partial colocalization with the membrane microdomains by immunofluorescence analysis. This discrepancy may be explained by the few contact points between CTXB and PCDH15 that exist in both UB/OC-1 cells and P1 mouse cochleae. A similar explanation can account for VLGR1. Only a small percentage $(\sim 2 \%)$ of the synaptic variants (Vlgr $1 b$ and Vlgr $1 m$ ) that cofractionate with GM1, localizes with the membrane microdomains and ribeye.

In an attempt to differentiate the apical and basal Usher vesicular subpools, we examined SNAP25 and rab5 as possible vesicular markers. SNAP25 is a peripheral plasma membrane
Table 2. Colocalization indexes between the vesicular markers, SNAP25 and rab5, and the Usher proteins

\begin{tabular}{|c|c|c|c|c|}
\hline & \multicolumn{2}{|l|}{ P1 cochlea } & \multicolumn{2}{|l|}{ UB/OC-1 } \\
\hline & $R r$ & ICQ & $R r$ & ICQ \\
\hline PCDH15(C) + SNAP25 & $+0.72 \pm 0.08$ & $+0.34 \pm 0.04$ & $+0.61 \pm 0.10$ & $+0.32 \pm 0.02$ \\
\hline VLGR1 EAR + SNAP25 & $+0.73 \pm 0.01$ & $+0.30 \pm 0.01$ & $+0.72 \pm 0.14$ & $+0.34 \pm 0.05$ \\
\hline$P C D H 15(M)+$ SNAP25 & $+0.71 \pm 0.03$ & $+0.29 \pm 0.05$ & $+0.67 \pm 0.06$ & $+0.34 \pm 0.03$ \\
\hline VLGR1 CT + SNAP25 & ND & ND & I & $+0.18 \pm 0.03$ \\
\hline PCDH15(C) + Rab5 & I & $+0.21 \pm 0.03$ & $+0.61 \pm 0.05$ & $+0.32 \pm 0.03$ \\
\hline VLGR1 EAR + Rab5 & I & $+0.23 \pm 0.05$ & $+0.59 \pm 0.12$ & $+0.33 \pm 0.07$ \\
\hline PCDH15(M) + Rab5 & $+0.61 \pm 0.20$ & $+0.23 \pm 0.12$ & $+0.56 \pm 0.09$ & $+0.35 \pm 0.04$ \\
\hline VLGR1 CT + Rab5 & $+0.60 \pm 0.07$ & $+0.31 \pm 0.03$ & $+0.73 \pm 0.04$ & $+0.31 \pm 0.02$ \\
\hline
\end{tabular}

In the case of P1 cochleae, the basal or apical regions were used to obtain the colocalization indexes between the Usher proteins and SNAP25 or rab5, respectively. In the case of UB/OC-1 cells the whole cell body (for SNAP25) or the perinuclear region (for rab5) were used to calculate the colocalization indexes. Two to three independent experiments were performed for P1 cochleae and two to five for UB/OC-1 cells. ND, Not determined; I, inconclusive.

associated protein that interacts with synaptobrevin and syntaxin I to form the soluble NSF ( $N$-ethylmaleimide-sensitive fusion protein) attachment protein receptor (SNARE) complex involved in synaptic vesicle docking at the site of neurotransmitter release (Oyler et al., 1989; Söllner et al., 1993; Safieddine and Wenthold, 1999; Wenthold et al., 2002). However, during brain and cochlea maturation, a role in synaptic development has been suggested for SNAP25 where SNAP25a is found primarily in vesicles (Mayanil and Knepper, 1993; Bark et al., 1995). Colocalization of SNAP2 5 and CDH23 has been demonstrated at the base of cochlear and vestibular hair cells and neuronal fibers (Lagziel et al., 2009).

Rab5 belongs to the family of small GTPases that play key roles in polarized trafficking, recycling, and motility of endosomes and in cell signaling (Lanzetti et al., 2000; Mottola et al., 2010). Rab5 shows expression in ciliated epithelia and apical colocalization with the Usher proteins has been previously demonstrated by our laboratory in mouse trachea (Tsarouhas et al., 2007; Zallocchi et al., 2010). Both SNAP25 and rab5 fractionate toward the top fractions in sucrose density gradients (Fig. 6), consistent with a vesicular localization and suggesting a possible interaction with the Usher proteins. Figure 10 shows P1 cochlea cross-sections immunostained for the "basal" Usher variants and SNAP25 (Fig. $10 A, B)$ and the "apical" Usher variants and rab5 (Fig. 10C,D). SNAP25 colocalizes with the PCDH15(C) and VLGR1 EAR variants at the base of the inner hair cells and to some degree at the base of the outer hair cells (high-magnification images). Conversely, there is colocalization between rab5 and VLGR1 CT or PCDH15(M) in the stereocilia (high-magnification images). The positive colocalization coefficients obtained by quantitative analysis confirm the associations with the corresponding vesicular proteins (Table 2).

Differentiated UB/OC-1 cells were also used to study the distribution of the Usher proteins relative to these two vesicular markers (Fig. 11). Again, there is colocalization between the Usher variants showing a filamentous pattern of staining and SNAP25 (Fig. 11A,B), and the ones that show perinuclear expression and rab5 (Fig. 11C,D). Although there is expression of the Usher proteins at the cell surface (arrowheads), the association with SNAP25 occurs intracellularly in SNAP25-positive vesicles, evident by the characteristic punctate pattern of immunostaining (high-magnified images in red). The perinuclear variants, PCDH15(M) and VLGR1 CT, show strong association with the apical vesicular marker rab5. While only a fraction of the PCDH15(M) variants-containing vesicles colocalize with rab5 (high-magnified images, arrowhead), the variants detected by the VLGR1 CT antibody show a strong association with rab5-positive tubulovesicular 

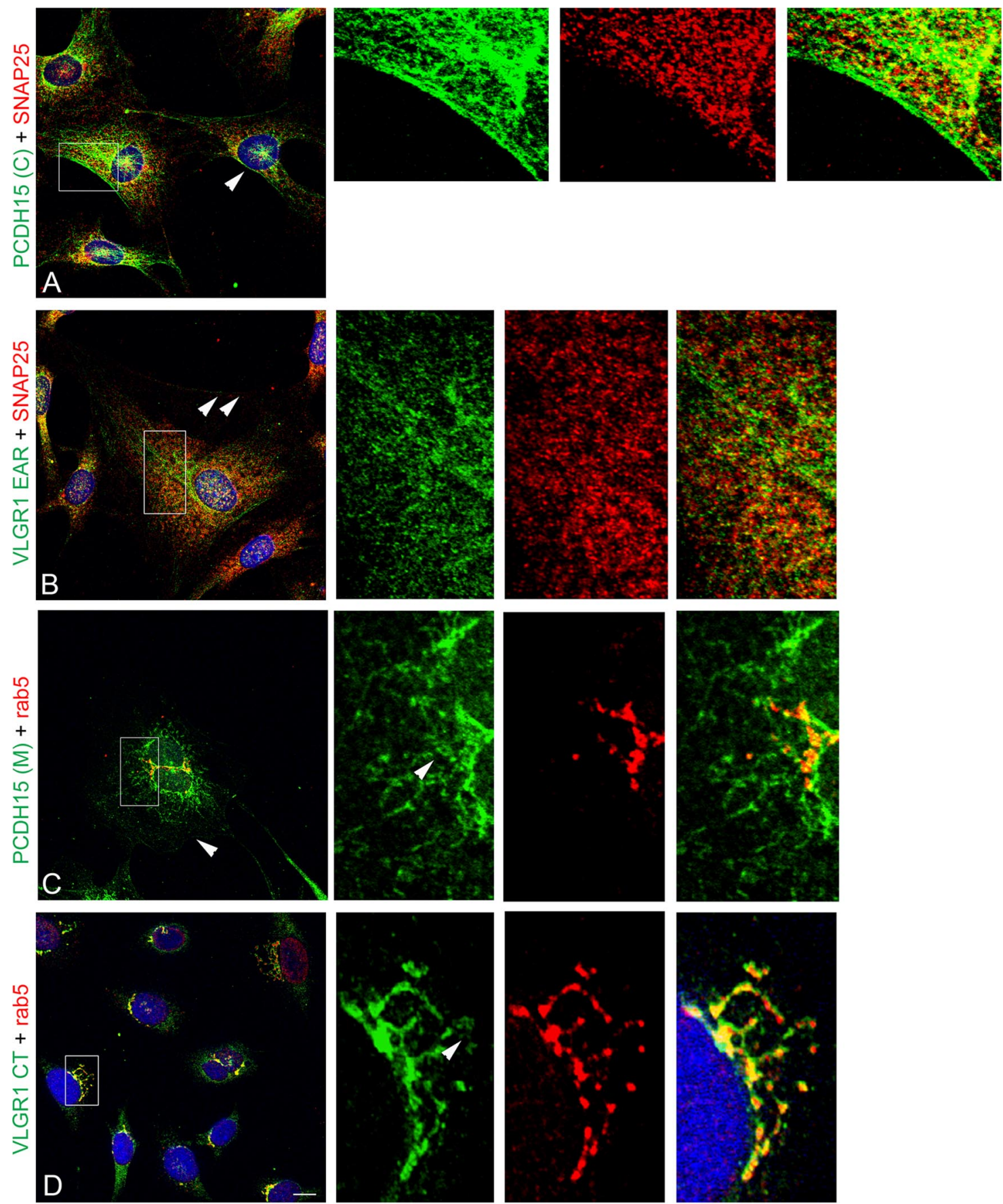

Figure 11. Colocalization analysis of the Usher proteins with SNAP25 and rab5 in differentiated UB/OC-1 cells. (ells were fixed and double immunostained for the Usher proteins (green) and the vesicular markers (red). A, PCDH15(C) + SNAP25. B, VLGR1 EAR + SNAP25. C, PCDH15(M) + rab5. D, VLGR1 CT + rab5. A-C, Arrowheads denote expression of the corresponding Usher protein at the cell surface. High-magnification images of the framed areas are shown to the right, arrowheads point to tubulovesicular structures that show the presence of the vesicular marker and the corresponding Usher protein. Scale bar, $10 \mu \mathrm{m}$.

structures. In some cases it is even possible to discriminate, within the same subcellular structure, the membrane-associated expression of VLGR1 CT versus the intra-tubulovesicular expression of rab5 (arrowhead in high magnified image).

A reciprocal set of immunolocalization experiments in cochleae and UB/OC-1 cells (Figs. 12, 13) and the corresponding colocalization indexes (Table 2) suggest there is an association between rab5 and the apical PCDH15(C) and VLGR1 EAR variants $(\mathrm{P} 1$ cochlea ICQs values $\approx+0.20, R r$ values inconclusive; $\mathrm{UB} / \mathrm{OC}-1$ cells ICQs values $\approx+0.30 ; R r$ values $\approx+0.60)$. On the other hand, we observe association between the postsynaptic variants detected by PCDH15(M) and SNAP25 (P1 cochlea ICQ value, $+0.29 ; R r$ value, +0.71 ; UB/OC- 1 cells ICQ value, +0.34 ; $R r$ value, +0.67$)$. As we expected, VLGR1 CT variants show little or no association with the basal vesicular marker SNAP25.

Finally, and because of the strong association between VLGR1 and both vesicular markers, SNAP25 $(R r>+0.70$ and ICQ $>+0.30$ for VLGR1 EAR) and rab5 $(R r \geq+0.60$ and ICQ $>+0.30$ for VLGR1 CT) in cochlea and UB/OC-1 cells, we decided to address whether a physical interaction exists between specific VLGR1 variants and the corresponding vesicular markers by coimmunoprecipitation studies. Figure 14 (top panels) demonstrates that there is 
indeed an association between SNAP25 and some of the VLGR1 synaptic variants (Zallocchi et al., 2012). We used both P1 inner ear and also P3 brain since SNAP25 and VLGR1 are highly coexpressed in the same cortical areas during brain development (Mayanil and Knepper, 1993; Bark et al., 1995; Yagi et al., 2005). The fact that we observed different variants immunoprecipitated from the inner ear (Vlgrlf/g/o and Vlgr1l) versus brain (Vlgr1m) suggests that the interactions between SNAP25 and the VLGR1 EAR variants are tissue specific (and likely developmentally regulated). The same conditions were used to analyze putative interactions between rab5 and VLGR1. Although no association was observed by coimmunoprecipitation studies (data not shown), the fact that both proteins colocalize in cochlea and cultured hair cells suggests that some interactions may exist but are not detectable by our assays. We used an alternative approach to test whether rab5 is influencing Usher protein trafficking by introducing, in UB/OC-1 cells, a constitutively active GFP-rab5 fusion protein (Rab5Q79L) that produces an enlargement of the early endosomes (Stenmark et al., 1994; Ezratty et al., 2009). Figure 14 (bottom panels) shows that a subset of the GFPpositive vesicles also contains VLGR1 CT antibody-reactive variants (Fig. $14 D-F$, arrowheads). Moreover, the overexpression of a constitutively active rab5 produces a saturation or hyperactivity of the general protein transport that results, as is the case for VLGR1 CT, in a mislocalization and expression at the tip of the cell's filopodia (framed area in Fig. $14 F$ and highmagnification images). The GFP-empty vector (GFP-EV) shows a more homogenous distribution for GFP and the normal perinuclear expression for VLGR1 CT (Fig. $14 A-C)$. These experiments suggest that although we were unable to see an association between rab5 and VLGR1 by coimmunoprecipitation, an indirect interaction may exist as demonstrated by the altered intracellular trafficking.

In summary, results from Figures 10-14 show there are indeed at least two distinct vesicular Usher complexes. The first one colocalizes with rab5 and traffics apically to the hair cell bundle, while the second one, through interactions between SNAP25 and VLGR1 synaptic variants (Zallocchi et al., 2012), traffics basally to the developing hair cells synapses.

\section{Discussion}

Although little is known regarding vesicle transport in hair cells, the fact that distinct functional specializations are present at opposite poles of the neurosensory epithelia predicts the existence
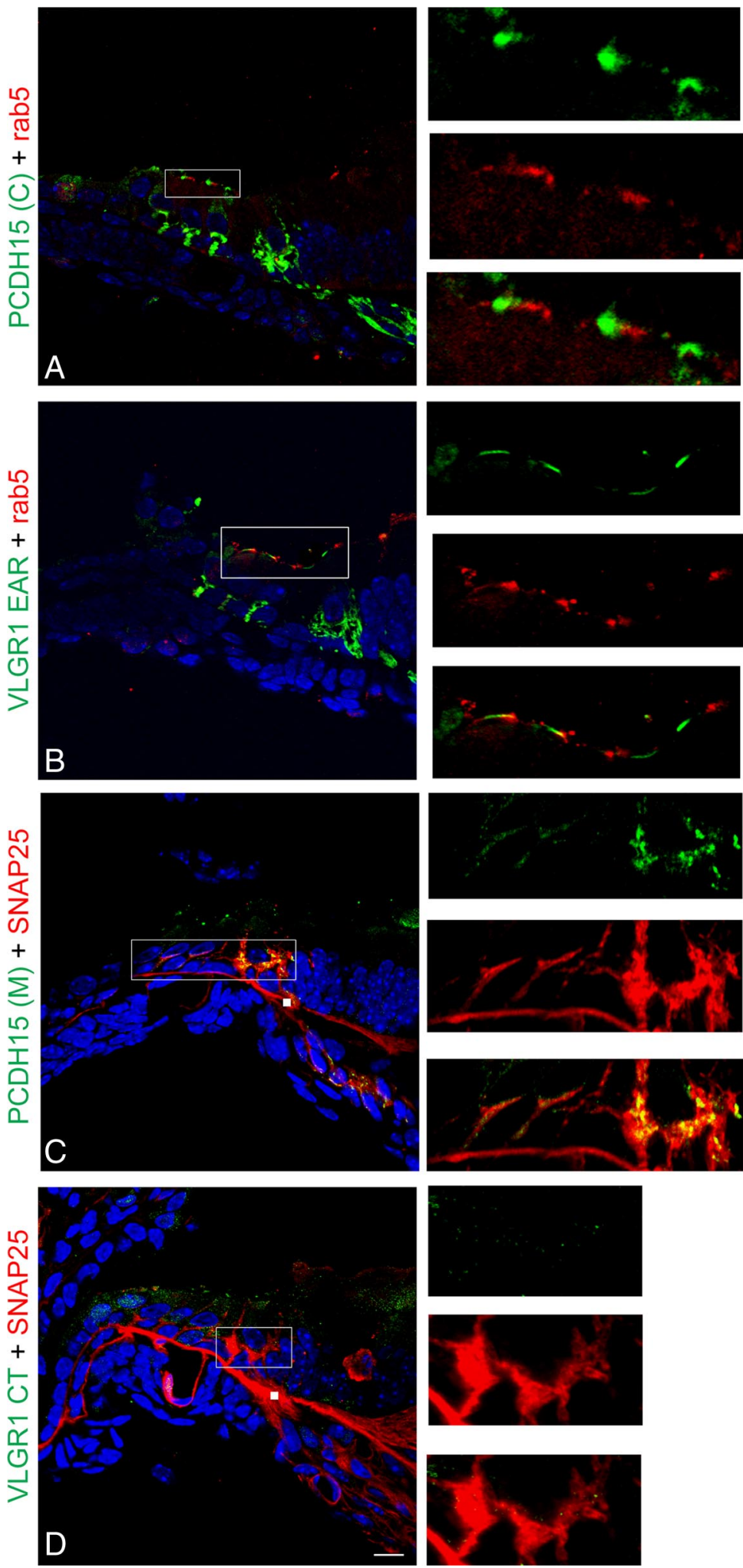

Figure 12. Reciprocal colocalization analysis of the Usher proteins with basal and apical vesicular markers in $P 1$ cochlea. $P 1$ cochlea cross-sections were double immunostained for the Usher proteins (green) and the vesicular markers (red). $\boldsymbol{A}, \mathrm{PCDH15}(\mathrm{C})+\operatorname{rab5}$. B, VLGR1 EAR + rab5.C, PCDH15(M) + SNAP25.D, VLGR1 CT + SNAP25. High magnification of the apical $(\boldsymbol{A}, \boldsymbol{B})$ or basal $(\boldsymbol{C}, \boldsymbol{D})$ regions is shown to the right. Scale bar, $10 \mu \mathrm{m}$. White squares in $C$ and $D$ represent nonspecific staining of the secondary mouse antibody. of regulated polarized vesicular trafficking mechanisms. The importance of this vesicular transport is evidenced by the large number of cytoskeletal adaptor proteins expressed by hair cells and by the discovery of hearing loss-associated diseases in which 

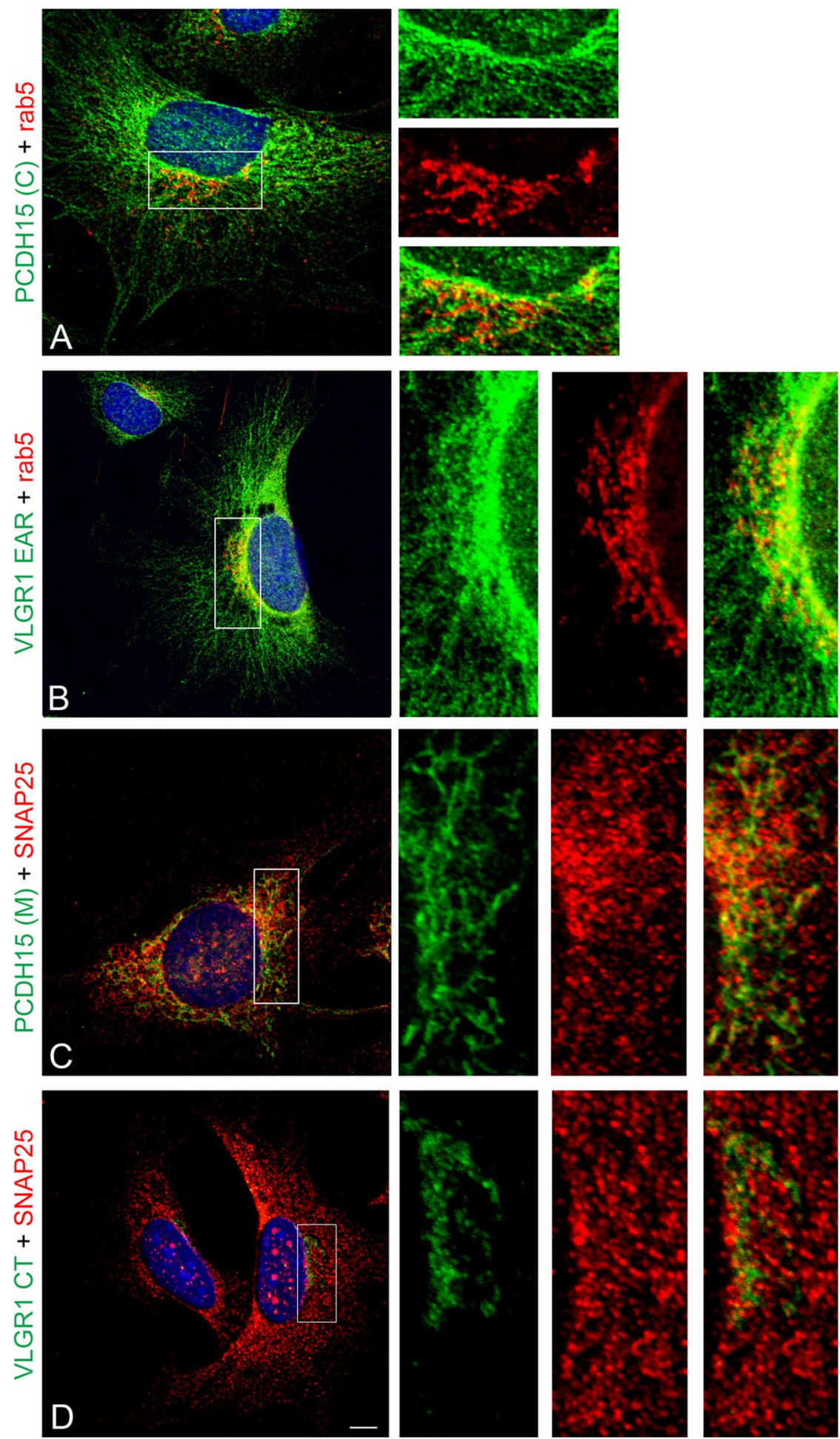

Figure 13. Reciprocal colocalization analysis of the Usher proteins with SNAP25 and rab5 in differentiated UB/OC-1 cells. Cells were fixed and double immunostained for the Usher proteins (green) and the vesicular markers (red). A, PCDH15(C) + rab5. B, VLGR1 EAR + rab5.C, PCDH15(M) + SNAP25. D, VLGR1 CT + SNAP25. High-magnification images of the framed areas are shown to the right. Scale bar, $7 \mu \mathrm{m}$.

their function is abrogated (Hasson et al., 1997; Boëda et al., 2002).

Through the use of multiple antibody preparations recognizing distinct antigenic regions of PCDH15 and VLGR1, we were able to establish the presence of two distinct vesicular subpools that traffic specific Usher variants to either the apical or basal poles in cochlear hair cells. One pool is associated to Arf1-positive vesicles and present at the apical aspect of the hair cells, while the other associates with post-trans-Golgi vesicles and localizes to the auditory synapses. The fact that A5 is a potent inhibitor of AP-1, an adaptor protein involved in basolateral trafficking in polarized epithelia (Carmosino et al., 2010), suggests that this particular vesicular subpool traffics Usher proteins to a basal destination in cochlear hair cells. Previous studies demonstrated that the incu- 
bation of HeLa cells with A5 produced a redistribution of AP-1 from the cytosol to perinuclear structures (Duncan et al., 2007). Similar results are shown in this work for the "basal" Usher variants, strongly supporting an association with AP-1-positive vesicles.

The association with the cytoskeletal machinery has already been described for several Usher proteins including PCDH15 (Adato et al., 2005). Colocalization studies with actin or tubulin show variations in the degree of interaction that each group of variants has with the cytoskeleton. There is a strong association of the "basal" Usher proteins with microtubules while a very weak interaction is observed between both group of variants, "apical" and "basal," and the actin cytoskeletal network. Although colocalization indexes are low for actin and the PCDH15(M) variants (ICQ +0.18), there is a strong association with the cortical actin network (ICQ: +0.33 ). In polarized epithelia the directional trafficking of cargo molecules involves transport along microtubules (Carmosino et al., 2010). It is likely a similar mechanism may exist for vesicle transport of Usher proteins in hair cells involving distinct microtubule adaptor proteins as route determinants. Once, for example, at the apical pole of the hair cells (or the cell surface in UB/OC-1 cells) as is the case for the PCDH15(M) variants, they are transferred to the actin network for their final destination, the tip link (Kazmierczak et al., 2007).

Our own previous work and that of others demonstrated the existence of vesicle-associated Usher protein complexes in ciliated epithelial cells and photoreceptors (Maerker et al., 2008; Zallocchi et al., 2010). Using nondetergent UB/OC-1 lysates as a source of Usher proteins, we observed two well defined pools of Usher variants after sucrose density gradient fractionation. One group comprised of most of the Usher variants, sediments into the buoyant fraction (11-14), while a second group fractionates into the middle of the gradient (7-9). The disparity in the molecular sizes within a specific Usher protein sedimenting together into the low density fractions and the fact that most of these Usher variants contain putative transmembrane domains suggest, as it was previously shown in tracheal epithelial cells, that they are associated with vesicles (Zallocchi et al., 2009).

In hair cells, as in any other polarized epithelia, the asymmetric distribution of plasma membrane proteins into apical (stereocilia bundle) and basolateral (ribbon synapses) domains depends on distinct trafficking characteristics. These include not
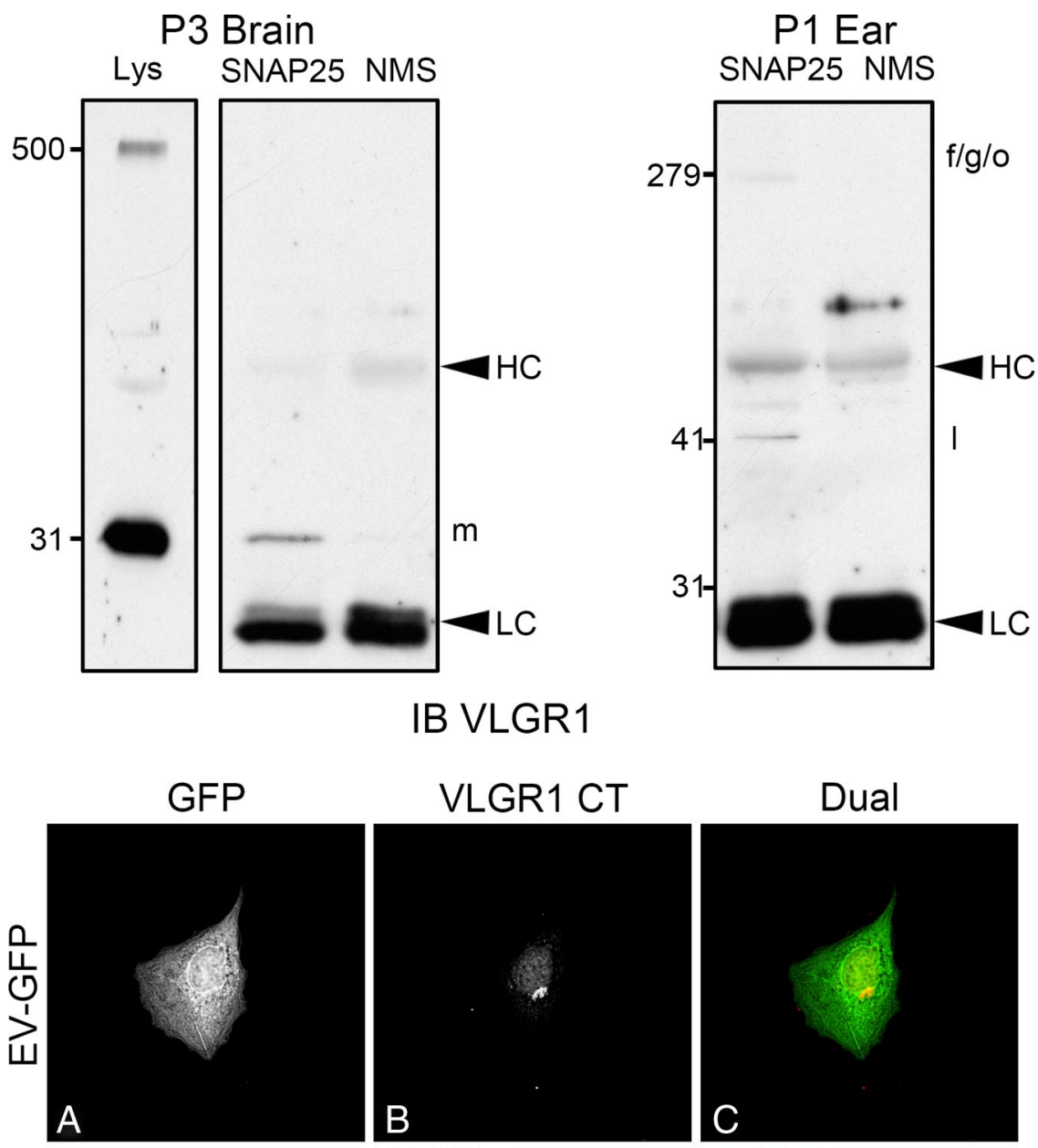

IB VLGR1
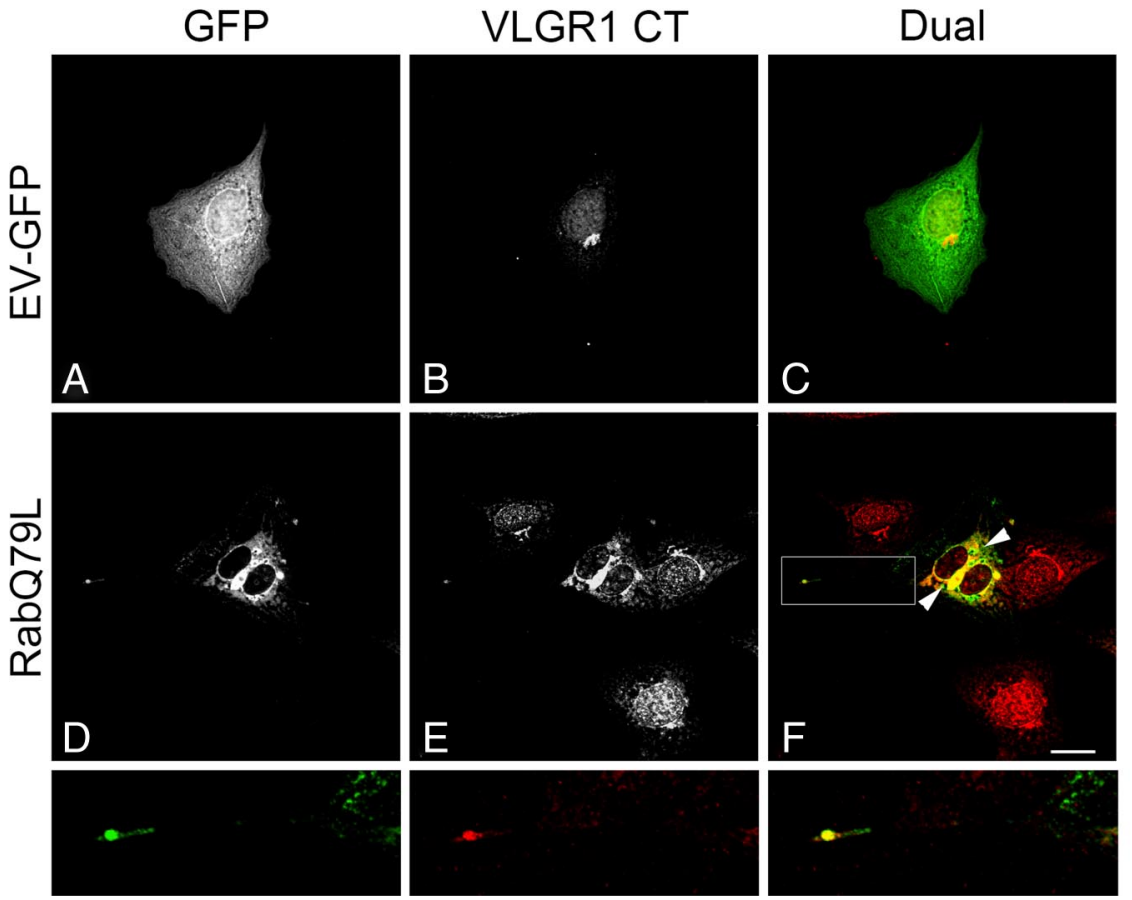

Figure 14. Specific VLGR1 EAR variants interact in vivo with SNAP25 while constitutive active rab5 influences VLGR1 trafficking. Top panels, Coimmunoprecipitation studies with anti-SNAP25 were performed in P3 brain (left panels) and P1 inner ear (right panel), followed by immunoblotting with anti-VLGR1 EAR (IB VLGR1). Lys, Total lysate from P3 brain. SNAP25, Specific coimmunoprecipitation with anti-SNAP25. NMS, Nonspecific coimmunoprecipitation with normal mouse serum. Note that there are only two main variants expressed in brain, the full-length (VIgr 16$)$ and the $30 \mathrm{kDa}$ synaptic variant $(V / g r 1 \mathrm{~m})$. Molecular weight markers are on the left ( $\mathrm{kDa}$ ). $\mathrm{HC}$, IgG heavy chain. LC, IgG light chain. Bottom panels, Differentiated UB/OC-1 cells were electroporated in the presence of GFP-empty vector (GFP-EV, $\boldsymbol{A}-\boldsymbol{C}$ ) or the constitutive active Rab5Q79L (D-F). After $48 \mathrm{~h}$ postelectroporation, cells were fixed and immunostained for GFP ( $(g r e e n, \boldsymbol{A}, \boldsymbol{D})$ and VLGR1 CT (red, $\boldsymbol{B}, \boldsymbol{E})$. Arrowheads denote GFP-positive vesicles; some of them containing VLGR1 CT. Framed area $(\boldsymbol{F})$ denote colocalization at the cell filopodia. High-magnification images correspond to the framed area. Scale bar, $20 \mu \mathrm{m}$.

only vesicle association to specific cytoskeletal adaptor proteins, but also presence of consensus motifs/conformations and/or posttranslational modifications within the cargo molecules, oligomerization, and differential affinity of the cargo proteins for small lipid rafts present in the vesicular membrane (RodriguezBoulan et al., 2005). The most accepted hypothesis for the apical 
sorting of cargo molecules postulates an association with membrane microdomains rich in glycosphingolipids and cholesterol. However, since several basolateral proteins also have a high affinity for the same type of membrane microdomains, it has been suggested that an association with those structures is necessary but not sufficient to target the vesicles to the correct destination (Paladino et al., 2004).

To elucidate whether an involvement of GM1-rich membrane microdomains may exist in Usher vesicular trafficking, we used two different approaches: DRMs fractionation from UB/OC-1 cells and colocalization studies in mouse cochlea and hair cells. To our surprise the results obtained contrast with the most accepted hypothesis that postulates apically sorted proteins have high affinity for membrane microdomains (Carmosino et al., 2010). Only a small fraction of the synaptic Usher variants is associated with these structures. The DRM fractionation experiments show the presence of at least two of the VLGR1 synaptic variants (Vlgrlb and Vlgrlm) (Zallocchi et al., 2012). Moreover, confocal colocalization studies in cochlea cross-sections show that the highest density of membrane microdomain punctae is present along the basolateral membrane and at the afferent neuronal terminals.

In UB/OC- 1 cells a common pattern is observed between the variants reacting basally in cochlear hair cells [PCDH15(C), PCDH15(M), and VLGR1 EAR] and GM1-positive microdomains. There is a high degree of colocalization at the tip of the cell filopodia, where the presynaptic protein ribeye is concentrated. Based on what we observed in DRM-fractionation experiments, only a few contacts exist between specific Usher variants and membrane microdomains. These observations, along with the interaction found between the VLGR1 synaptic variants and SNAP25 and the recent emerging evidence of a role for some Usher protein variants in synaptogenesis (Gregory et al., 2011; Phillips et al., 2011; Zallocchi et al., 2012), imply that membrane microdomains may also be involved in ribbon synapse organization, maturation, and perhaps function.

The possible association of the Usher complexes with SNAP25 during cochlear development is also of interest. Previous reports have shown a developmental upregulation of SNAP25 protein during synaptogenesis and neuronal maturation (Mayanil and Knepper, 1993; Bark et al., 1995) with a broader pattern of expression compared with adult nervous system. Moreover, there is a shift in SNAP25 subcellular localization from synaptic vesicles to synaptic membranes during development, suggesting a spatiotemporal regulation for this SNARE (Oyler et al., 1989; Mayanil and Knepper, 1993). The possible involvement of SNAP25 in hair cell ribbon synapse maturation has already been suggested by Sendin et al. (2007), where thyroid hormone plays a key role in SNAP25 upregulation.

The results presented here, colocalization of SNAP25 and the Usher proteins at the base of the hair cells at the postnatal developmental time when the synapses are undergoing active remodeling, the presence of these proteins in the same vesicular pool, and the interaction between SNAP25 and VLGR1, argue in favor of a putative Usher:SNAP25 synaptic complex involved in postnatal synaptic development in cochlear hair cells.

Although apical expression of rab5 has been shown in different polarized epithelia (Tsarouhas et al., 2007; Zallocchi et al., 2010; Clark et al., 2011), this is the first report demonstrating its expression at the stereocilia bundle in auditory hair cells in higher vertebrates. Rab5 plays a key role in endosome fusion during receptor-mediated endocytosis acting on the EEA1 (early endosomal autoantigen 1) effector protein and promoting vesicle teth- ering and membrane fusion (Chamberlain et al., 2010). The observation that the highest colocalization occurs with VLGR1 CT and PCDH15(M) variants, both in cochleae and UB/OC-1 cells, and that a constitutively active form of rab5 produces the mislocalization of VLGR1 CT to the cell filopodia, suggests an involvement (direct or indirect) of this small GTPase in the apical trafficking of vesicles transporting Usher protein complexes.

Rab5 activity is regulated by Esp8 through the recruitment of one of its GTPase-activating factors (GAP) (Lanzetti et al., 2000). Esp8 is also involved in stereocilia development with Esp8 mutant animals presenting shorter stereocilia in cochlear hair cells (Manor et al., 2011). Most of the Usher mouse models display varying degrees of stereocilia abnormalities, suggesting that these proteins function at different levels in the process of hair bundle development (McGee et al., 2006; Lefèvre et al., 2008; Geng et al., 2009). Some of these mutants also display protein trafficking defects in photoreceptor cells suggesting Usher proteins are playing a role in protein transport (Peng et al., 2011). Investigating whether Usher proteins may associate with rab5 and affect the apical trafficking of the tri-partite complex, Esp8-GAP-rab5, necessary for stereocilia elongation, is now an open question that needs to be addressed not only to gain a better understanding of Usher syndrome pathology but also the more general mechanism of stereocilia maturation.

Altogether the results presented in this work support the existence of at least two distinct pools of Usher variants that move in vesicles to opposite poles of the hair cells. The recognition of specific markers or tags within those vesicles by the cytoskeletal and trafficking machinery allows the correct targeting to their final destination where they likely play key roles in the maturation of both stereocilia and ribbon synapses.

\section{References}

Adato A, Lefèvre G, Delprat B, Michel V, Michalski N, Chardenoux S, Weil D, El-Amraoui A, Petit C (2005) Usherin, the defective protein in Usher syndrome type IIA, is likely to be a component of interstereocilia ankle links in the inner ear sensory cells. Hum Mol Genet 14:3921-3932.

Ahmed ZM, Riazuddin S, Ahmad J, Bernstein SL, Guo Y, Sabar MF, Sieving P, Riazuddin S, Griffith AJ, Friedman TB, Belyantseva IA, Wilcox ER (2003) PCDH15 is expressed in the neurosensory epithelium of the eye and ear and mutant alleles are responsible for both USH1F and DFNB23. Hum Mol Genet 12:3215-3223.

Ahmed ZM, Goodyear R, Riazuddin S, Lagziel A, Legan PK, Behra M, Burgess SM, Lilley KS, Wilcox ER, Riazuddin S, Griffith AJ, Frolenkov GI, Belyantseva IA, Richardson GP, Friedman TB (2006) The tip-link antigen, a protein associated with the transduction complex of sensory hair cells, is protocadherin-15. J Neurosci 26:7022-7034.

Ahmed ZM, Kjellstrom S, Haywood-Watson RJ, Bush RA, Hampton LL, Battey JF, Riazuddin S, Frolenkov G, Sieving PA, Friedman TB (2008) Double homozygous waltzer and Ames waltzer mice provide no evidence of retinal degeneration. Mol Vis 14:2227-2236.

Alagramam KN, Miller ND, Adappa ND, Pitts DR, Heaphy JC, Yuan H, Smith RJ (2007) Promoter, alternative splice forms and genomic structure of protocadherin 15. Genomics 90:482-492.

Alagramam KN, Goodyear RH, Geng R, Furness DN, van Aken AF, Marcotti W, Kros CJ, Richarson GP (2011) Mutations in protocadherin 15 and cadherin 23 affect tip links and mechanotransduction in mammalian sensory hair cells. PLoS ONE 6:e19183.

Bark IC, Hahn KM, Ryabinin AE, Wilson MC (1995) Differential expression of SNAP25 protein isoforms during divergent vesicle fusion events of neural development. Proc Natl Acad Sci U S A 92:1510-1514.

Boëda B, El-Amraoui A, Bahloul A, Goodyear R, Daviet L, Blanchard S, Perfettini I, Fath KR, Shorte S, Reiners J, Houdusse A, Legrain P, Wolfrum U, Richardson G, Petit C (2002) Myosin VIIa, harmonin and cadherin 23 , three Usher I gene products that cooperate to shape the sensory hair cell bundle. EMBO J 21:6689-6699.

Boughman JA, Vernon M, Shaver KA (1983) Usher syndrome: definition 
and estimate of prevalence from two high risk populations. J Chronic Dis 36:595-603.

Brown DA, London E (1998) Functions of lipid rafts in biological membranes. Annu Rev Cell Dev Biol 14:111-136.

Brown DA, Rose JK (1992) Sorting of GPI-anchored proteins to glycolipidenriched membrane subdomains during transport to the apical cell surface. Cell 68:533-544.

Carmosino M, Valenti G, Caplan M, Svelto M (2010) Polarized traffic towards the cell surface: how to find the route. Biol Cell 102:75-91.

Chamberlain MD, Oberg JC, Furber LA, Poland SF, Hawrysh AD, Knafelc SM, McBride HM, Anderson DH (2010) Deregulation of Rab5 and Rab4 proteins in p85R274A-expressing cells alters PDGFR trafficking. Cell Signal 22:1562-1575.

Clark BS, Winter M, Cohen AR, Link BA (2011) Generation of rab-based transgenic lines for in vivo studies of endosome biology in zebrafish. Dev Dyn 240:2452-2465.

Deretic D, Papermaster DS (1991) Polarized sorting of rhodopsin on postGolgi membranes in frog retinal photoreceptor cells. J Cell Biol 113:1281-1293.

Duijsings D, Lanke KH, van Dooren SJ, Dommelen MM, Wetzels R, de Mattia F, Wessels E, van Kuppeveld FJ (2009) Differential Membrane Association Properties and Regulation of Class I and Class II Arfs. Traffic 10:316323.

Duncan MC, Ho DG, Huang J, Jung ME, Payne GS (2007) Composite synthetic lethal identification of membrane traffic inhibitors. Proc Natl Acad Sci U S A 104:6235-6240.

Ezratty EJ, Bertaux C, Marcantonio EE, Gundersen GG (2009) Clathrin mediates integrin endocytosis for focal adhesion disassembly in migrating cells. J Cell Biol 187:733-747.

Geng R, Geller SF, Hayashi T, Ray CA, Reh TA, Bermingham-McDonogh O, Jones SM, Wright CG, Melki S, Imanishi Y, Palczewski K, Alagramam KN, Flannery JG (2009) Usher syndrome IIIA gene clarin-1 is essential for hair cell function and associated neural activation. Hum Mol Genet 18: $2748-2760$

Grati M, Kachar B (2011) Myosin VIIa and sans localization at stereocilia upper tip-link density implicates these Usher syndrome proteins in mechanotransduction. Proc Natl Acad Sci U S A 108:11476-11481.

Gregory FD, Bryan KE, Pangršič T, Calin-Jageman IE, Moser T, Lee A (2011) Harmonin inhibits presynaptic $\mathrm{Ca}_{\mathrm{V}} 1.3 \mathrm{Ca}^{2+}$ channels in mouse inner hair cells. Nat Neurosci 14:1109-1111.

Hallgren B (1959) Retinitis pigmentosa combined with congenital deafness; with vestibule-cerebellar ataxia and neural abnormality in a proportion of cases: a clinical and genetico-statistical study. Acta Psychiatr Scand Suppl 34:1-101.

Hasson T, Gillespie PG, Garcia JA, MacDonald RB, Zhao Y, Yee AG, Mooseker MS, Corey DP (1997) Unconventional myosins in inner-ear sensory epithelia. J Cell Biol 137:1287-1307.

Kazmierczak P, Sakaguchi H, Tokita J, Wilson-Kubalek EM, Milligan RA, Müller U, Kachar B (2007) Cadherin 23 and protocadherin 15 interact to form tip-link filaments in sensory hair cells. Nature 449:87-91.

Kremer H, van Wijk E, Märker T, Wolfrum U, Roepman R (2006) Usher syndrome: molecular links of pathogenesis, proteins and pathways. Hum Mol Genet 2:R262-R270.

Lagziel A, Overlack N, Bernstein SL, Morell RJ, Wolfrum U, Friedman TB (2009) Expression of cadherin 23 isoforms is not conserved: implications for a mouse model of Usher syndrome type 1D. Mol Vis 15:1843-1857.

Lajoie P, Kojic LD, Nim S, Li L, Dennis JW, Nabi IR (2009) Caveolin-1 regulation of dynamin-dependent, raft-mediate endocytosis of cholera toxin-B sub-unit occurs independently of caveolae. J Cell Mol Med 13: $3218-3225$.

Lanzetti L, Rybin V, Malabarba MG, Christoforidis S, Scita G, Zerial M, Di Fiore PP (2000) The Eps8 protein coordinates EGF receptor signaling through Rac and trafficking through Rab5. Nature 408:374-377.

Lefèvre G, Michel V, Weil D, Lepelletier L, Bizard E, Wolfrum U, Hardelin JP, Petit C (2008) A core cochlear phenotype in USH1 mouse mutants implicates fibrous links of the hair bundle in its cohesion, orientation and differential growth. Development 135:1427-1437.

Lelli A, Kazmierczak P, Kawashima Y, Müller U, Holt JR (2010) Development and regeneration of sensory transduction in auditory hair cells requires runctional interaction between Cadherin-23 and Protocadherin-15. J Neurosci 30:11259-11269.

Le-Niculescu H, Niesman I, Fischer T, DeVries L, Farquhar MG (2005)
Identification and characterization of GIP, a novel Galpha i/s-interacting protein found on COPI, endoplasmic reticulum-Golgi transport vesicles. J Biol Chem 280:22012-22020.

Li Q, Lau A, Morris TJ, Guo L, Fordyce CB, Stanley EF (2004) A syntaxin 1, G $\alpha_{\mathrm{o}}$ and $\mathrm{N}$-type calcium channel complex at a presynaptic nerve terminal: analysis by quantitative immunolocalization. J Neurosci 24:4070-4081.

Maerker T, van Wijk E, Overlack N, Kersten FF, McGee J, Goldmann T, Sehn E, Roepman R, Walsh EJ, Kremer H, Wolfrum U (2008) A novel Usher protein network at the periciliary reloading point between molecular transport machineries in vertebrate photoreceptor cells. Hum Mol Genet 17:71-86.

Manor U, Disanza A, Grati M, Andrade L, Lin H, Di Fiore PP, Scita G, Kachar B (2011) Regulation of stereocilia length by myosin XVa and whirlin depends of the actin-regulatory protein Eps8. Curr Biol 21:167-172.

Mayanil CS, Knepper PA (1993) Synaptic vesicle and synaptic membrane glycoproteins during pre- and postnatal development of mouse cerebral cortex, cerebellum and spinal cord. Dev Neurosci 15:133-145.

McGee J, Goodyear RJ, McMillan DR, Stauffer EA, Holt JR, Locke KG, Birch DG, Legan PK, White PC, Walsh EJ, Richardson GP (2006) The very large G-protein-coupled receptor VLGR1: a component of the ankle link complex required for the normal development of auditory hair bundles. J Neurosci 26:6543-6553.

McMillan DR, White PC (2004) Loss of the transmembrane and cytoplasmic domains of the very large G-protein-coupled receptor-1 (VLGR1 or Mass1) causes audiogenic seizures in mice. Mol Cell Neurosci 26:322329.

Michalski N, Michel V, Bahloul A, Lefèvre G, Barral J, Yagi H, Chardenoux S, Weil D, Martin P, Hardelin JP, Sato M, Petit C (2007) Molecular characterization of the ankle-link complex in cochlear hair cells and its role in the hair bundle functioning. J Neurosci 27:6478-6488.

Mottola G, Classen AK, González-Gaitán M, Eaton S, Zerial M (2010) A novel function for the rab5 effector rabenosyn-5 in planar cell polarity. Development 137:2353-2364.

Nichols BJ, Kenworthy AK, Polishchuk RS, Lodge R, Roberts TH, Hirschberg K, Phair RD, Lippincott-Schwartz J (2001) Rapid cycling of lipid raft markers between the cell surface and Golgi complex. J Cell Biol 153:529541.

Owen DM, Magenau A, Majumdar A, Gaus K (2010) Imaging membrane lipid order in whole, living vertebrate organisms. Biophys J 99:L07-L09.

Oyler GA, Higgins GA, Hart RA, Battenberg E, Billingsley M, Bloom FE, Wilson MC (1989) The identification of a novel synaptosomal-associated protein, SNAP-25, differentially expressed by neuronal subpopulations. J Cell Biol 109:3039-3052.

Paladino S, Sarnataro D, Pillich R, Tivodar S, Nitsch L, Zurzolo C (2004) Protein oligomerization modulates raft partitioning and apical sorting of GPI-anchored proteins. J Cell Biol 167:699-709.

Paladino S, Lebreton S, Tivodar S, Campana V, Tempre R, Zurzolo C (2008) Different GPI-attachment signals affect the oligomerisation of GPIanchored proteins and their apical sorting. J Cell Sci 121:4001-4007.

Peng YW, Zallocchi M, Wang WM, Delimont D, Cosgrove D (2011) Moderate light-induced degeneration of rod photoreceptors with delayed transducing translocation in shaker1 mice. Invest Ophthalmol Vis Sci 52:6421-6427.

Petit C (2001) Usher syndrome: from genetics to pathogenesis. Annu Rev Genomics Hum Genet 2:271-297.

Phillips JB, Blanco-Sanchez B, Lentz JJ, Tallafuss A, Khanobdee K, Sampath S, Jacobs ZG, Han PF, Mishra M, Titus TA, Williams DS, Keats BJ, Washbourne P, Westerfield M (2011) Harmonin (Ush1c) is required in zebrafish Müller glial cells for photoreceptor synaptic development and function. Dis Model Mech 4:786-800.

Reiners J, Märker T, Jürgens K, Reidel B, Wolfrum U (2005a) Photoreceptor expression of the Usher syndrome type 1 protein protocadherin 15 (USH1F) and its interaction with the scaffold protein harmonin (USH1C). Mol Vis 11:347-355.

Reiners J, van Wijk E, Märker T, Zimmermann U, Jürgens K, te Brinke $\mathrm{H}$, Overlack N, Roepman R, Knipper M, Kremer H, Wolfrum U (2005b) Scaffold protein harmonin (USH1C) provides molecular links between Usher syndrome type 1 and type 2. Hum Mol Gen 14:3933-3943.

Reiners J, Nagel-Wolfrum K, Jürgens K, Märker T, Wolfrum U (2006) Molecular basis of human Usher syndrome: deciphering the meshes of the Usher protein network provides insights into the pathomechanisms of the Usher disease. Exp Eye Res 83:97-119. 
Rivolta MN, Grix N, Lawlor P, Ashmore JF, Jagger DJ, Holley MC (1998) Auditory hair cell precursors immortalized from the mammalian inner ear. Proc Biol Sci 265:1595-1603.

Rivolta MN, Halsall A, Johnson CM, Tones MA, Holley MC (2002) Transcript profiling of functionally related groups of genes during conditional differentiation of a mammalian cochlear hair cell line. Genome Res 12:1091-1099.

Safieddine S, Wenthold RJ (1999) SNARE complex at the ribbon synapses of cochlear hair cells: analysis of synaptic vesicle- and synaptic membraneassociated proteins. Eur J Neurosci 11:803-812.

Sato B, Katagiri YU, Miyado K, Okino N, Ito M, Akutsu H, Okita H, Umezawa A, Fujimoto J, Toshimori K, Kiyokawa N (2011) Lipid rafts enriched in monosialylGb5Cer carrying the stage-specific embryonic antigen-4 epitope are involved in development of mouse preimplantation embryos at cleavage stage. BMC Dev Biol 11:22.

Seiler C, Nicolson T (1999) Defective calmodulin-dependent rapid apical endocytosis in zebrafish sensory hair cell mutants. J Neurobiol 41:424-434.

Seiler C, Finger-Baier KC, Rinner O, Makhankov YV, Schwarz H, Neuhauss SC, Nicolson T (2005) Duplicated genes with split functions: independent roles of protocadherin 15 orthologues in zebrafish hearing and vision. Development 132:615-623.

Sendin G, Bulankina AV, Riedel D, Moser T (2007) Maturation of ribbon synapses in hair cells is driven by thyroid hormone. J Neurosci 27:3163-3173.

Senften M, Schwander M, Kazmierczak P, Lillo C, Shin JB, Hasson T, Géléoc GS, Gillespie PG, Williams D, Holt JR, Müller U (2006) Physical and functional interaction between protocadherin 15 and myosin VIIa in mechanosensory hair cells. J Neurosci 26:2060-2071.

Simons K, Ikonen E (1997) Functional rafts in cell membranes. Nature 387:569-572.

Skradski SL, Clark AM, Jiang H, White HS, Fu YH, Ptácek LJ (2001) A novel gene causing a mendelian audiogenic mouse epilepsy. Neuron 31:537-544.

Söllner T, Whiteheart SW, Brunner M, Erdjument-Bromage H, Geromanos S, Tempst P, Rothman JE (1993) SNAP receptors implicated in vesicle targeting and fusion. Nature 362:318-324.

Staub E, Pérez-Tur J, Siebert R, Nobile C, Moschonas NK, Deloukas P, Hinzmann B (2002) The novel EPTP repeat defines a superfamily of proteins implicated in epileptic disorders. Trends Biochem Sci 27:441-444.

Stenmark H, Parton RG, Steele-Mortimer O, Lütcke A, Gruenberg J, Zerial M
(1994) Inhibition of rab5 GTPase activity stimulates membrane fusion in endocytosis. EMBO J 13:1287-1296.

Tian G, Zhou Y, Hajkova D, Miyagi M, Dinculescu A, Hauswirth WW, Palczewski K, Geng R, Alagramam KN, Isosomppi J, Sankila EM, Flannery JG, Imanishi Y (2009) Clarin-1, encoded by the Usher Syndrome III causative gene, forms a membranous microdomain: possible role of clarin-1 in organizing the actin cytoskeleton. J Biol Chem 284:18980-18993.

Tsai SC, Adamik R, Haun RS, Moss J, Vaughan M (1993) Effects of brefeldin A and accessory proteins on association of ADP-ribosylation factors 1, 3, and 5 with Golgi. J Biol Chem 268:10820-10825.

Tsarouhas V, Senti KA, Jayaram SA, Tiklová K, Hemphälä J, Adler J, Samakovlis C (2007) Sequential pulses of apical epithelial secretion and endocytosis drive airway maturation in Drosophila. Dev Cell 13:214-225.

van Wijk E, van der Zwaag B, Peters T, Zimmermann U, Te Brinke H, Kersten FF, Märker T, Aller E, Hoefsloot LH, Cremers CW, Cremers FP, Wolfrum U, Knipper M, Roepman R, Kremer H (2006) The DFNB31 gene product whirlin connects to the Usher protein network in the cochlea and retina by direct association with USH2A and VLGR1. Hum Mol Genet 15:751-765.

Webb SW, Grillet N, Andrade LR, Xiong W, Swarthout L, Della Santina CC, Kachar B, Müller U (2011) Regulation of PCDH15 function in mechanosensory hair cells by alternative splicing of the cytoplasmic domain. Development 138:1607-1617.

Wenthold RJ, Safieddine S, Ly CD, Wang YX, Lee HK, Wang CY, Kachar B, Petralia RS (2002) Vesicle targeting in hair cells. Audiol Neurootol 7:45-48.

Yagi H, Takamura Y, Yoneda T, Konno D, Akagi Y, Yoshida K, Sato M (2005) Vlgr1 knockout mice show audiogenic seizure susceptibility. J Neurochem 92:191-202.

Yagi H, Tokano H, Maeda M, Takabayashi T, Nagano T, Kiyama H, Fujieda S, Kitamura K, Sato M (2007) Vlgr1 is required for proper stereocilia maturation of cochlear hair cells. Genes Cells 12:235-250.

Zallocchi M, Meehan DT, Delimont D, Askew C, Garige S, Gratton MA, Rothermund-Franklin CA, Cosgrove D (2009) Localization and expression of clarin-1, the Clrn1 gene product, in auditory hair cells and photoreceptors. Hear Res 255:109-120.

Zallocchi M, Sisson JH, Cosgrove D (2010) Biochemical characterization of native Usher protein complexes from a vesicular subfraction of tracheal epithelial cells. Biochemistry 49:1236-1247.

Zallocchi M, Meehan DT, Delimont D, Rutledge J, Gratton MA, Flannery J, Cosgrove D (2012) Role for a novel Usher protein complex in hair cell synaptic maturation. PLoS One 7:e30573. 